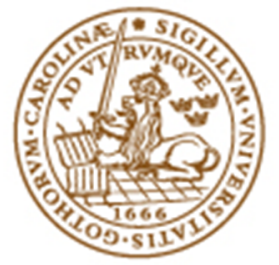

LUND UNIVERSITY

School of Economics and Management

\title{
A COEXCEEDANCE APPROACH ON FINANCIAL CONTAGION
}

Author: Dinh-Vinh Vo

ID: 860712 - 9015

Supervisor: Lu Liu

Lund, May 2013 


\section{ACKNOWLEDGEMENTS}

Foremost, I would like to express my sincere gratitude to my supervisor, Lu Liu, for her guide and persistent support. Not only has she taken her time and patience to give me a number of valuable suggestions, but also showed me the most suitable approach to address the research questions. She has always kept track of my thesis to ensure that I was on the right progress.

I am also indebted to Tuan-Minh Nguyen at Department of Mathematics, who has always offered me his enthusiastic assistance to better understand various statistical and mathematical issues.

I would like to extend my thanks to mid-term and final seminar participants, especially Heinz Munzinger, and Shangjie Liu for insightful comments. Their valuable suggestions have helped me to refine the paper.

I am grateful to Vietnam International Education Development for their financial assistant.

Last but not least, I would like to express the deepest gratitude to my family for their spiritual support through my life.

Lund, May 2013.

Dinh-Vinh Vo 


\begin{abstract}
The paper sheds light on financial contagion within the Euro Area and Asia, and contagion from the Euro Area to Asia during two recent crises: the global financial crisis and European sovereign debt crisis. Applying the multinomial logit regression model, the paper investigates how the macro-finance variables affect the coincidence of extreme negative returns (coexceedances). In addition, I apply both original constant threshold i.e. 5\% percentile of unconditional distribution of daily stock returns and Value-at-Risk to estimate extreme negative returns. These approaches offer a similar pattern. The empirical findings reveal that, in the Euro Area and Asia, the probability of the occurrence of coexceedances is strongly explained by the idiosyncratic risks: the changes in exchange rates, the regional stock market volatility, and global shocks: the changes in the U.S. long-term interest rates, the TED spread. The global volatility index is only significant to explain the likelihood of coexceedances in the Euro Area, not in Asia. These analyses lead to the conclusion that contagion in Asia is more important than in the Euro Area. Another important finding indicates the existence of contagion from the Euro Area to Asia. That is, the probability of coexceedances in Asia is predictable and depends on the number of joint occurrence of extreme return shocks in the Euro Area.
\end{abstract}

Keywords: financial contagion, coexceedance, regional macro-finance variables, global shocks, multinomial logit model. 


\section{Contents}

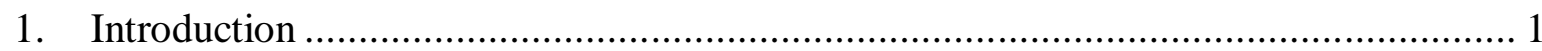

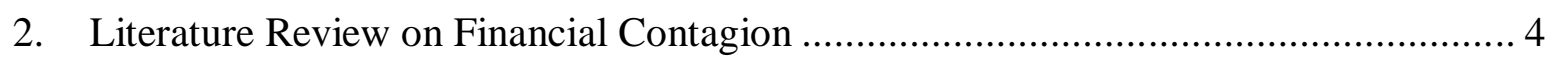

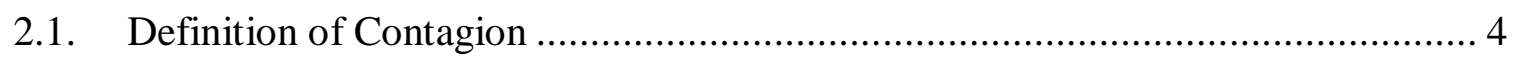

2.2. Empirical evidence on financial contagion ......................................................... 6

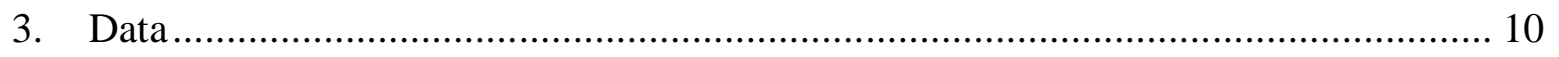

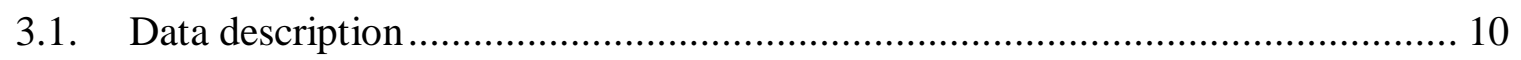

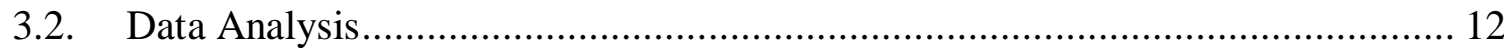

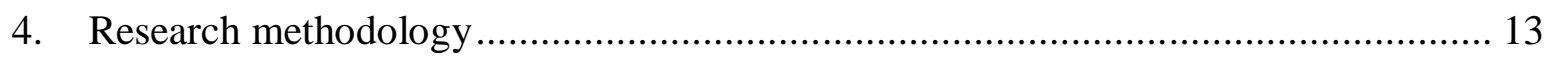

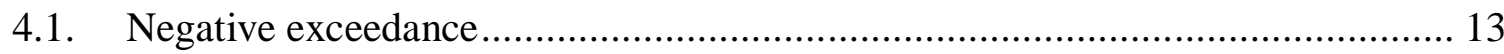

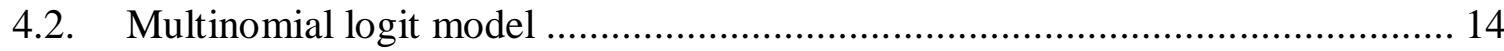

4.3. Exceedance estimation using Value-at-Risk ………………………………... 17

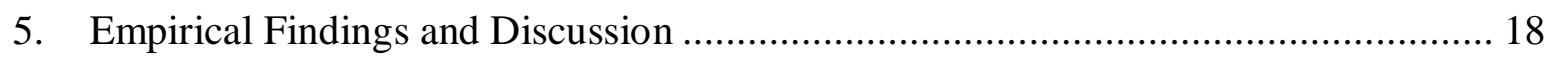

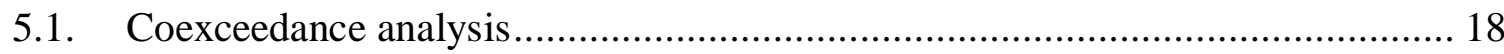

5.2. Contagion within the Euro Area and within Asia............................................ 19

5.3. Contagion from the Euro Area to Asia ……………….................................... 33

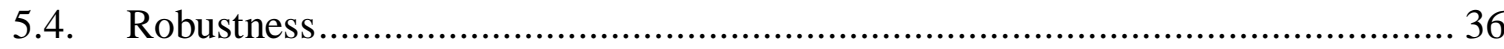

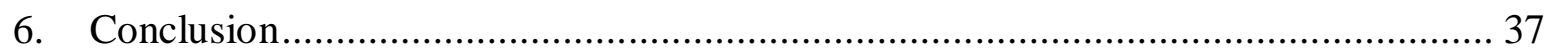

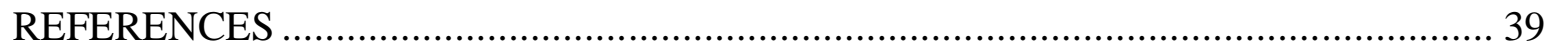

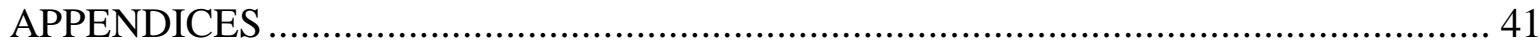




\section{Tables}

Table 1: Summary statistics of (co-exceedances) for daily stock market index returns in the Euro Area and Asia countries

Table 2: Contagion test results of multinomial logit regression for daily negative coexceedances within the Euro Area and Asia in two cases: with and without controlling for global shocks.............................................................................................. 24

Table 3: Contagion test from the Euro Area to Asia, January 2, 2007, to March 28, 2013. 34

\section{Figures}

Figure 1: Stock market indices in Global Financial Crisis and European Sovereign Debt Crisis. ............................................................................................................ 2

Figure 2: Rolling window of size 500 for VaR estimation .......................................... 18

Figure 3: Time Series Plot of the Negative Coexceedance in the Europe Area and Asia

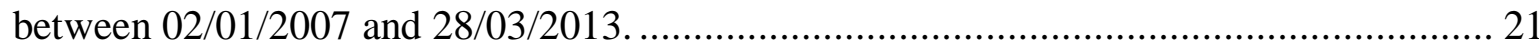

Figure 4: Coexceedance response curves of negative extreme returns in the Euro Area and Asia ......................................................................................................... 29

Figure 5: Coexceedance response curves of negative extreme returns in the Euro Area and Asia to global shocks

Figure 6: Coexceedance response curves of negative extreme returns in Asia to the number of coexceedances and the volatility of stock returns in the Euro Area.... 
"A disease that can be communicated rapidly through direct or indirect contact" - a definition of contagion from Webster's dictionary.

\section{Introduction}

The series of financial crises in recent three decades have reflected the interdependence of global stock markets. Increasing integration no doubt has led the co-movement of global financial markets during tranquil and crisis times. Financial integration, on the one hand, provides investors to allocate assets world-wide. On the other hand, if correlations of stock markets increase significantly during crisis, the co-movement itself reduces the diversification benefits across international stock markets and affects the efficiency of macroeconomic policies. Through channels of transmission e.g. trade linkages and financial linkages, crises are likely to spread from a "diseased" country to a "healthy" one, causing a number of deleterious impacts. Before 1997, the term of "contagion" rarely appeared in economics or financial economics. However, this term since the East Asian currency collapse has been considered as the standard lexicon to refer to the breadth of the crises ${ }^{1}$. A crisis not only results in recession in stock markets, it also places a heavy burden on the macroeconomic fundamentals. For instance, in 2009, the unemployment rate reached above 9\% in the Euro Area. Government deficits approached 6.3\% of GDP, whereas the debt ratio reached around $80 \%$ of $\mathrm{GDP}^{2}$. The two most recent crises, namely the global financial crisis and European sovereign debt crisis, not only cause catastrophic losses in the U.S. and the Euro Area, but also are propagated across countries. As shown in Figure 1, the global financial crisis resulted in substantial toll on the Euro Area and Asian stock markets. However, the effects of the European Sovereign Debt Crisis are not identical across countries in both regions. The outstanding questions are that if these stock markets experience large negative returns simultaneously induced by the tumultuous periods, is this case considered as contagion? If yes, are there contagion within the Euro Area and Asia? Are extreme negative returns in the Euro Area transmitted to Asia?

\footnotetext{
${ }^{1}$ See Forbes (2012) who uses Factiva's statistics to find the number of economic/financial articles referring to contagion.

${ }^{2}$ Eurostat
} 

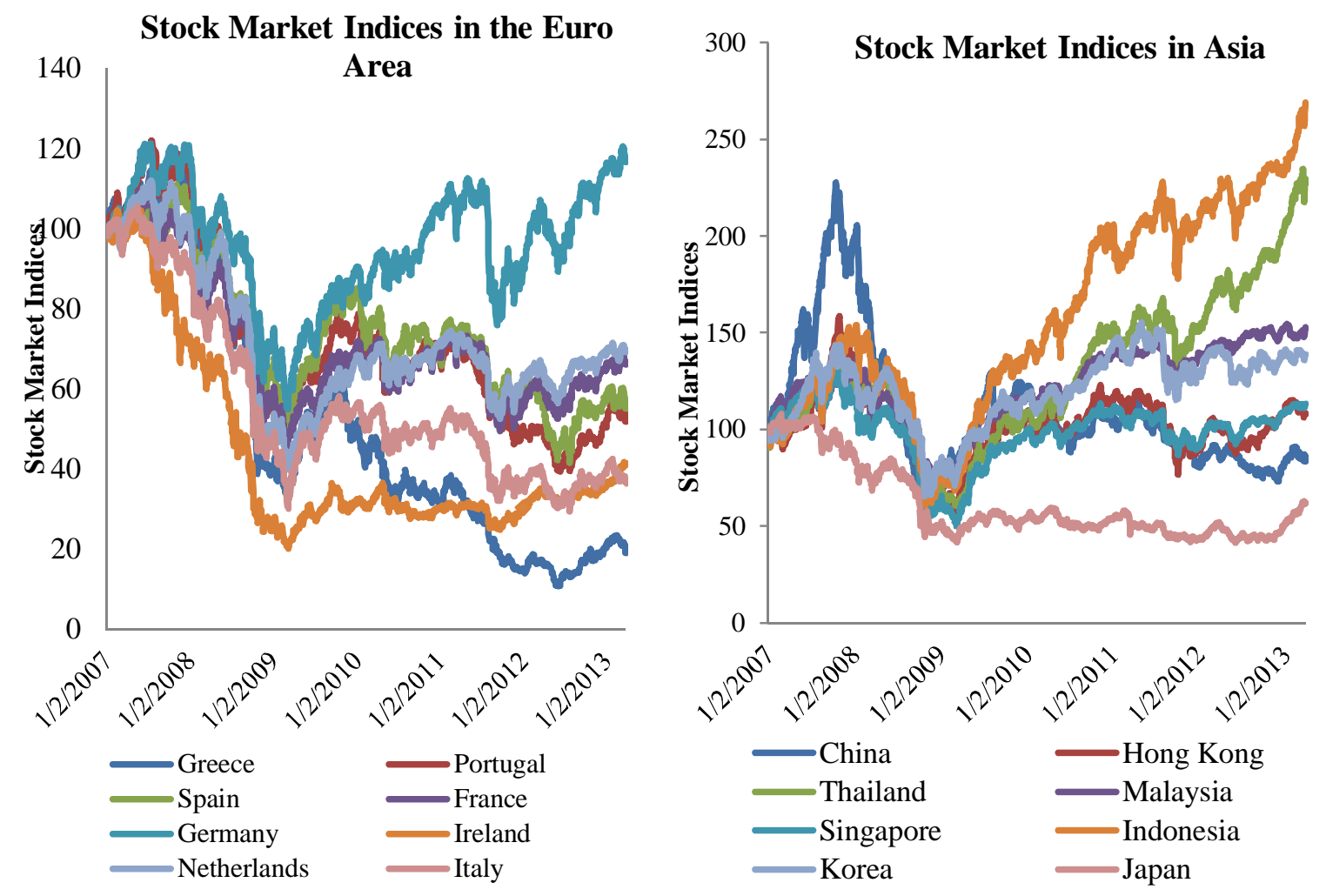

Figure 1: Stock market indices in Global Financial Crisis and European Sovereign Debt Crisis.

The figures show stock market indices for 8 countries in the Euro Area countries and 8 countries in Asia from $02 / 01 / 2007$ to $28 / 03 / 2013$. Indices are set to 100 on the starting day.

Study of contagion would provide better understanding of the interdependence of international financial markets, thus allow investors to obtain the optimal diversification strategy and policy makers to stabilize the financial system.

The paper aims at exploring if there is the presence of contagion in the Euro Area and Asian countries. Financial contagion, in this paper, will be measured by analyzing coincidence of exceedances. Exceedances are defined as extreme negative returns that are below a certain threshold in one country, whereas coexceedances are the joint occurrences of exceedances in two or more stock markets. To evaluate contagion within region, I identify if macro-finance variables (covariates) contribute significantly to the occurrence of negative events in the Euro Area and Asian countries. By this way, I am able to explore various impacts of covariates on coexceedances. Following the interpretation of Bae, Karolyi, and Stulz (2003), I define contagion within region as the fraction of the coexceedances that is left unexplained by the macro - finance variables such as the changes 
in short - term interest rates, the changes in exchange rates, and the market volatility. Additionally, I examine the impacts of the number of joint negative exceedances in the Euro Area on the number of joint negative exceedances in Asia. In particular, I address the question that whether the number of coexceedances in Asia can be predicted by the given number of joint occurrence of negative extreme returns in the Euro Area. Contagion across regions is defined as the fraction of the coexceedances in Asia that are probably attributed to coexceedances in the Euro Area, but unexplained by its own covariates.

The paper contributes to the existing literature in twofold perspectives. First, a substantial literature has recently applied a coexceedance approach to verify contagion in different financial asset markets since Bae et al. (2003) first developed this methodology in 2003. However the empirical literature using a coexceedance approach to detect contagion from the highly integrated area i.e. the Euro Area to Asia in two recent financial crises is less common. Therefore, the paper aims at filling the gap in the previous studies by examining whether there exists transmission of financial turmoil across regions. However, departing from Bae et al. (2003), I focus only on extreme negative stock market returns. This is because the policymakers are more probably concerned with negative events spreading out of their control, and investors are normally downside-risk averse (Liu (2011)). Furthermore, in spite of controlling for common shocks, Forbes (2012) does not focus on their impacts. Ismailescu and Kazemi (2011) use merely two global factors in the multinomial logit regression. I extend their studies by taking global shocks into account to explain a part of coexceedances that can be unexplained by the regional factors. Second, besides using the same threshold which is determined by $5 \%$ percentile of the unconditional return distribution for the whole data sample (See e.g. Bae et al. (2003), Ismailescu and Kazemi (2011) , Forbes (2012), Christiansen and Ranaldo (2009)), I employ historical simulation to estimate Value-at-Risk ( $\mathrm{VaR})$, then exceedances are identified to be lower than VaR. Using VaR would permit threshold vary over time, thereby better reflect heavy losses in the tremendous turmoil period.

My thesis is implemented in four stages: I start by estimating the coincidence of negative exceedances. Next I include more regional explanation variables to test contagion within region as well as to determine the channels through which crisis is propagated internationally. However, as a proxy of contagion, the occurrence of coexceedances could 
be caused by the global shocks i.e. extraordinary changes in global factors. Hence, I will delve deeply into measuring contagion after controlling for global shocks. Eventually, the number of coexceedances and the volatility of the Euro Area stock markets are complemented to detect contagion from the Euro Area to Asia.

The thesis is organized as follows: Section 2 presents literature review on financial contagion, including the definitions, contagion measures and empirical results. Section 3 describes the data. Section 4 provides methodology to detect financial contagion. Section 5 shows the empirical results, discussion and robustness. Section 6 contains conclusions.

\section{Literature Review on Financial Contagion}

The empirical literature on the occurrence of financial contagion is extensive. Not only is the precise definition of contagion questionable, but a standard methodology to measure transmission of financial turmoil remains to be reached. This section represents how contagion is defined and discusses advantages and disadvantages of various empirical approaches to detect contagion. Empirical evidences are also provided in this section.

\subsection{Definition of Contagion}

The definition of contagion has still been ambiguous in the financial literature. This section only aims at introducing three most representative definitions of contagion.

Forbes and Rigobon (2001) define contagion as a significant increase in co-movement in financial turmoil. In other words, in spite of high correlated markets, the contagion does not occur unless the co-movement increases significantly in the crisis times. Forbes and Rigobon (2002) call this co-movement interdependence if the correlations across countries are high in all states: tranquil and crisis periods. The strictest definition of contagion is commonly applied thanks to its attraction ${ }^{3}$. This definition does not emphasize on measuring different propagation transmission channels. It permits us to test contagion across both countries and asset classes straightforwardly. Unfortunately, if the correlation

\footnotetext{
${ }^{3}$ See for example Boyer, Kumagai, and Yuan (2006); Caporale, Cipollini, and Spagnolo (2005), Chiang, Jeon, and Li (2007); Naoui, Liouane, and Brahim (2010); Essaadi, Jouini, and Khallouli (2009); Cho and Parhizgari (2008)
} 
increases in the crisis period, the challenge is how to identify the higher correlation is caused by the propagation or the outcome of the change in volatility. Thus, testing for the presence of contagion using correlation estimates, due to heteroskedasticity, leads to biasness according to Forbes and Rigobon (2002). A number of papers recently addressed this issue by accounting for time-varying volatilities. These researches are discussed in more detail in next part.

Another definition related to cross-country comovement is excess correlation that cannot be explained by fundamentals (Bekaert, Harvey, and $\mathrm{Ng}$ (2005), Bekaert, Ehrmann, Fratzscher, and Mehl (2011)). It means the fundamentals-based transmission occurring during crisis would not qualify as contagion. The insolvency of Greek government, for instance, may cause credit losses of French banks because of their substantial ownership of Greek debt. Since the negative shock is spread through the financial linkages, this transmission is not considered as evidence of contagion. As a consequence, before appraising the presence of contagion, we have to identify how a crisis propagates through the underlying fundamentals. This definition is commonly used to investigate the impacts of herding behavior on the vulnerability of the financial system.

The broadest definition is refereed as a shock that is propagated from a stock market to others, especially during turmoil period (Kodres and Pritsker (2002)). This definition is preferred by policymakers as Vitor Constancio (Vice-president of ECB) once wrote: "...financial contagion refers to a situation whereby instability in a specific market or institution is transmitted to one or several other markets or institutions." Most studies explain that contagion is qualified if the shock transmission is not explained by financial and trade linkages or other fundamentals (Forbes (2012)). In my paper, I describe a shock as an event where an extreme negative return spreads from one country to others. Consistent with Bae et al. (2003), I measure contagion as the fraction of negative coexceedance events that are not explained by the macro - finance variables included in the model. This definition, accordingly, better captures the nonlinear phenomena e.g. integration and contagion. In addition, it may overcome the weakness of the correlation coefficient that tends to be biased due to heteroskedasticity. The possible drawbacks of this 
definition are the small sample size of extreme returns, and the possibility of global shock causing extreme returns. The paper also addresses these problems.

\subsection{Empirical evidence on financial contagion}

In their paper, Forbes and Rigobon (2001), Dungey, Fry, González-Hermosillo, and Martin (2005) review a range of different methodologies applied in empirical studies to test the presence of financial contagion including: Cointegration, autoregressive and heteroskedastic dynamics, correlation and covariance analysis, and probit models. Nevertheless, no approach is able to address all questions associated with omitted variables, nonlinearity and conditional and unconditional heteroskedasticity simultaneously. Consequently, the existence of contagion has not been conclusive. This section discusses various methodologies and empirical evidences on financial contagion.

A common approach to investigate financial contagion is to compare the correlations between two markets during the turbulence period and non-crisis period. As pointed out by Forbes and Rigobon (2002), heteroskedasticity in financial markets results in biased correlation coefficients. In particular, an increase in market volatility due to crisis may cause the conditional correlation coefficient to be greater. Hence, a higher correlation coefficient during tumultuous periods may be the result of a statistical artifact. After correcting for heteroskedasticity, they do not find contagion, but there are the strong linkages among countries, which is so-called interdependence, during the U.S. stock market crash, the Mexican Peso crisis and the East Asian crisis. Forbes (2012) analyzes the impacts of changes in volatility and global shocks on the bilateral comovement in 48 equity markets from 1980 to 2012. The results show that volatility and global factors do not contribute to the greater correlations. Stock market comovement appears to increase and become more interdependent, which is not necessary to qualify contagion. Bordo and Murshid (2000) reach similar conclusion. That is, other studies exaggerate the presence of contagion. However, Dungey et al. (2005) point out that the correlation adjustment of Forbes and Rigobon (2002) is a conservative test since it rejects the null hypothesis of contagion frequently. These results are generally opposite to the findings of Favero and Giavazzi (2002) who find the evidences of contagion in all investigated cases. Baig and Goldfajn (1998) measure the cross-market correlations during the 1997-1998 East Asia crisis. They 
find the correlation coefficients increase significantly between the equity markets of Indonesia and Malaysia, but not between Malaysia and Thailand, Philippines and Indonesia. Boyer et al. (2006) consider excess correlation as a significant increase in comovement between returns of accessible stocks, inaccessible stocks and the crisis country index returns. Two categories, namely, those stocks that are eligible for non-local investors to purchase and those that are only accessible for domestic investors, are classified separately in order to verify if there exists the investor-induced contagion or the fundamental-based contagion. Then using a regime-switching model and extreme value theory to estimate correlation dynamics, they find an increase in co-movement during crisis regimes. Bekaert et al. (2005) apply two-factor asset pricing model and measure contagion as the correlation of unexpected returns. The results indicate that the Mexican crisis causes no additional contagion within Latin America, in Asia and Europe. The 1997-1998 East Asia crisis not only leads to an increase in the correlation within Asia, but also worsen contagion in Latin America and Europe.

Other studies address the issue of contagion of stock markets with dynamic conditional correlation model (DCC). (e.g. Caporale et al. (2005), Chiang et al. (2007), Naoui et al. (2010), Essaadi et al. (2009), Cho and Parhizgari (2008)). The model allows us not only to estimate the time-varying correlations between many asset markets directly but also cope with heteroskedasticity problems. Being inconsistent with Forbes and Rigobon (2002), Chiang et al. (2007) and Syllignakis and Kouretas (2011) provide the evidence of financial contagion due to herding behavior during the financial crisis. In line with this stream of the empirical findings, Chiang et al. (2007) and Missio and Watzka (2011) find the sensitivity of correlation coefficients to the credit-rating, thus conclude that contagion impacts on other countries might be severe due to the rating downgrades. Unfortunately, detecting contagion using DCC-GARCH still comes under several criticisms (Billio, Duca, and Pelizzon (2003); Billio and Pelizzon (2003)). When the crisis windows are predetermined, the model is unable to address heteroskedasticity completely. In addition, the low power of DCC test is shown when more than markets are studied jointly. According to Bae et al. (2003), extreme returns occur more frequently in crisis time. However, correlation is discerned to be linear, i.e. in correlation measure the small and large returns are weighted equally, hence the propagation across countries may be hidden. As a result, correlation 
measure is not the appropriate approach to assess the impact of extreme returns in the volatile period.

Further, investigating the channels of contagion associated with global shocks, country shocks and idiosyncratic shocks, Dungey and Martin (2007) illustrates the present of both spillover effects and contagion, and that the former outweighs the latter. The influence of contagion channels varies in different crisis from 1998 to 2007 ( e.g. Dungey, Fry, Martin, Tang, and González-Hermosillo (2010)). Particularly, the contagion channels have great impacts in the Russian/ Long-Term Capital Management, and the global financial crisis, but are less important in other crises. Baur (2012) whose study based on both the aggregate and sector level data shows the important role of financial stocks in the spread of the 2007-2009 global financial crisis. The analysis demonstrates an increase in co-movement of financial sector across countries. The result also gives a strong support for contagion between financial stocks and "real economy" stocks e.g. Consumer Goods, Industrials, and Technology within a country and across countries. To incorporate fundamentals in capturing the impacts of economic news on contagion, Baig and Goldfajn (1998) map fundamentals to dummy variables and find the occurrence of contagion across countries in the currency and equity markets. Glick and Rose (1999) estimate the binary probit model to investigate the impacts of macroeconomic phenomena on five currency episodes. Only trade channel is associated with the speculative attacks. Kodres and Pritsker (2002) elaborate a multiple asset rational expectation model to investigate the determinants of financial contagion. They find the evidence that contagion is attributed to cross-market rebalancing. This channel is helpful to clarify contagion between Asia and Latin America. By rebalancing their portfolio's exposure to macroeconomic uncertainty, market participants could shift idiosyncratic shocks from one country to others in spite of the weak linkages between two countries or two regions.

In contrast to the conventional methodologies, Bae et al. (2003) introduces a new approach to detect contagion using coexceedance definition. Accordingly, coexceedance is defined as the joint occurrences of extreme returns. This approach brings us a number of benefits. Firstly, coexceedance approach could overcome the econometric problems associated with the correlation estimation - including heteroskedasticity, nonlinearity. More 
importantly, it is possible to analyze contagion within region and across regions. By elaborating a multinomial logit regression model, the approach is able to capture the available information causing the exceedance events. Therefore, the model is also widely applied to investigate integration (Christiansen and Ranaldo (2009)), co-movement across international borders (Lin and Cheng (2008)), to design the warning system for crisis (Ciarlone and Trebeschi (2005), and Bussière and Fratzscher (2006)). Bae et al. (2003) focus on the number of joint occurrences of extreme returns to study contagion effects in emerging countries. The paper provides clear evidence of contagion depending on interest rates, conditional stock return volatility and exchange rates. However, Christiansen and Ranaldo (2009) analyzing coexceedances in 10 new EU members cannot find the importance of interest rates to the likelihood of observing extreme returns. Follow the same approach, Thomadakis (2012) test for contagion within Euro Area and from the US to Europe in the period of 2004-2011. The results imply that the regional covariates such as the Euro Area 10 year government bond yield and the changes in exchange rate is not statistically significant to explain the probabilities of coexceedance. Therefore, there exists contagion within Euro Area. However, Thomadakis (2012) cannot find contagion, but the interdependence between the US and Europe as the number of exceedances in the US fails to explain the probabilities of coexceedance in Europe. Ismailescu and Kazemi (2011) studying on the emerging credit markets find the presence of contagion within and across regions in the Russian crisis of 1998 and the Argentine crisis of 2001. Additionally, the authors apply correlation approach and find the striking outcome that contagion in emerging European and Latin American debt markets is likely to occur in both crisis and tranquil periods. Therefore, only interdependence, not contagion is observed in these markets. The main disadvantages of the approach applied by Bae et al. (2003) are the small sample size of extreme returns, and the possibility of global shock causing extreme return. Forbes (2012) takes the common shock into account to avoid the latter caveat. Departing from Bae et al. (2003), Forbes (2012) uses weekly data and examine the behavior of extreme negative returns only. Her study shows that crisis is transmitted through different channels such as trade linkages, banks and lending institutions, portfolio investors, and wake-up calls or credit rating. The paper also suggests that a vulnerable country to 
contagion normally own high leveraged banking system, weak macroeconomic fundamentals, and high trade exposure.

\section{Data}

The section starts with introducing which stock markets are analyzed, then I interpret the meaning and reasons of selecting explanatory variables. The last part also mentions data analysis for further evaluation in the succeeding sections.

\subsection{Data description}

I consider daily stock market indices in the Euro Area and Asia markets. A drawback of coexceedance approach is that the number of coexceedances might be insufficient for the regression. I opt for daily frequency since there is more possible for exceedances to occur, thereby increasing the size of coexceedances. In addition, a high frequency better captures different shocks which are supposed to affect stock markets speedily. The Euro Area countries consists of 8 countries, namely Greece (GRE), Portugal (POR), Spain (SPN), Italy (ITA), Ireland (IRE), Germany (GER), France (FRA), and the Netherlands (NEL). We consider the following 8 Asian stock markets: China (CHN), Hong Kong (HKG), Thailand (THL), Malaysia (MAL), Singapore (SGP), Indonesia (IND), Korea (KOR) and Japan

(JPN). I construct daily log returns by applying the formula: $r_{t}=\ln \left(\frac{P_{t}}{P_{t-1}}\right)$. In the analysis below, I use local currency returns to avoid the impact of the risk of exchange rates relative to the dollar.

Note that there is possible limitation of measuring contagion using coexceedance approach. That is, extreme negative returns could be caused by global shock, rather than by regional shocks. To address this disadvantage, I include more four variables as proxies of global shocks: the commodity price index changes, the U.S. long-term interest rates changes, the TED spread, and the VIX. Those variables respond with inflation, liquidity and credit risk, and investor's sentiment (see e.g. McGuire and Schrijvers (2003), Remolona, Scatigna, and Wu (2007) Dornbusch, Park, and Claessens (2001), Metiu (2011) and Forbes (2012)). The commodity price shocks (e.g. the 1973 oil crisis and the 2007 2008 world food price crisis) are one of the most important threats to the global shocks. 
Therefore, the commodity price index is expected to be negatively related to the likelihood of coexceedances. The U.S. long-term interest rates frequently reflect long-term macroeconomic expectations, thereby affect global stock prices. In fact, Bernanke (2013) concludes that the U.S. long-term interest rates reveals the expected real short-term interest rates, expected inflation, and term premium. As a consequence, the low level of those factors represents the weakness of the economy in developed countries. According to these arguments, I expect a negative relation between the changes in the U.S. long-term interest rates with the probability of the joint occurrences of exceedances. The TED spread is the difference between 3-month US Treasury Bill rate and 3-month LIBOR. The indicator presumably captures liquidity pressures and credit risk. An increase in the size of gap implies higher risk premium to compensate risk of the lenders in the short-term credit market, and vice versa. Hence, I expect a negative impact of the spread on probabilities of coexceedances. That is, an increase in the TED spread may lead to an increase in the probability of the joint occurrences. The VIX (The CBOE Volatility Index), based on implied volatility of S\&P 500 Index Options, is a key measure of market expectations of short-term volatility and could be considered as investors' sentiments. The higher VIX is assumed to increase the investors' aversion toward the international risks. Thus I expect a rise in VIX to be positively related to the probability of observing coexceedances.

Understanding the channels of contagion is the key issue to mitigate the deleterious impacts of financial crisis. Thus, to capture the transmission mechanism, I relate coexceedances to additional explanatory variables. Dornbusch et al. (2001) review various fundamental causes for contagion including common shocks, trade links, and financial links. However, the macroeconomic variables are mostly associated with low frequency, and stock market indices are estimated with daily data. Consequently, the estimation will become more complicated using mixed - frequency data. My paper uses macro - finance variables whose frequency is consistent with that of stock market return. Since I expect that if short-term interest rates increase, which reflects higher cost of capital, contagion is more likely to happen, I take into account the changes in regional short-term interest rates i.e. 1month EURIBOR for the Euro Area and 1-month SIBOR for Asia. To investigate whether the currency market can explain the likelihood of negative extreme returns, I add the changes in exchange rates. I use USD/EUR (the units of euro to exchange for one dollar) 
for the Euro Area markets and the equal-weighted average changes in exchange rates for Asian countries. Using the arguments of Christiansen and Ranaldo (2009), I expect the exchange rate movement to be connected with coexceedances in stock markets. Additionally, high volatility is more likely to happen in crises, thus I take into account the volatility of regional index. The volatility should exhibit positive relation with the probability of coexceedances within a region.

Data covers for the period from 02/01/2007 to 28/03/2013, including 1628 observations. For the estimation of Value-at-Risk, the data sample is extended 500 observations ahead, i.e. the sample period starts on 02/01/2005.

Non-trading days such as national holidays, the extraordinary technique incident are not included. Additionally, because of synchronous trading hours, for investigating financial contagion within region, I will match all available information up to time $t$ in U.S. with trading activities at time $t+1$ in the Euro Area and Asian stock markets. Contrarily, I use same trading day for data of these two regions to analyze contagion from the Euro Area to Asia.

All data are obtained from Datastream and defined in Appendix 1.

\subsection{Data Analysis}

Panel A in Appendix 2 provides descriptive statistics for the stock market index returns for all countries. Panel B illustrates unconditional correlations among countries in each region. All countries have trivial mean returns, whereas the daily return standard deviation is worth considering. Other statistical properties of the indices vary considerably across regions. The standard deviation of the stock markets in the Euro Area is greater than that in Asia. Greece has the largest standard deviation (2.1\%), the lowest one belongs to Malaysia $(0.9 \%)$. Spain experiences the highest positive extreme return (13.5\%), whereas Ireland obtains the largest negative extreme return (-14\%). Along with Portugal, Ireland, and Netherlands, Asian countries experience negative skewness, indicating that the return distributions with long left tail tend to extend toward the negative returns. Except for Greece market, all indices have positive kurtosis, implying the leptokurtic return distributions. Therefore, for those 
stocks, the extreme returns would arise more frequently than they would do under the mesokurtic distribution.

It is understandable to realize that correlations within the Euro Area stock markets are higher than those within Asian stock markets, where most correlation coefficients in the Euro Area are above 0.5. The advanced countries e.g. Germany and France, Netherlands and France exhibit extraordinarily high correlations of more than 0.7 .

\section{Research methodology}

The paper owes most to a recently developed coexceedance approach by Bae et al. (2003).

\subsection{Negative exceedance}

The first step is to construct extreme returns based on the existing literature, e.g. Bae et al. (2003), Christiansen and Ranaldo (2009), Forbes (2012). Since this approach lessens the sample size, instead of measure correlations of large-return shocks, I pay attention to the number of extreme returns. Exceedances are defined as negative extreme returns that lie below the $5 \%$ percentile (bottom tail) of the overall return distribution. The $5 \%$ threshold works well with the large data sample. Also, it ensures that the number of coexceedances is sufficient to apply the multinomial logit model. Coexceedance is expressed as the coexistence of extreme values at a same point of time. It can be defined mathematically as follows:

$$
\text { Coexceedances }=N\left(r_{i j} \mid r_{i j}<\alpha_{i, 0.05}\right)
$$

where $N($.$) is the number of countries in the region j, j=$ Euro Area, Asia; $r_{i j}$ denotes the returns of stock market $i$ in the region $j ; \alpha_{0.05}$ is the $5 \%$ percentile of the distribution of stock market $i$ 's return. Therefore, the number of coexceedances is counted by the number of countries simultaneously having an exceedance at a particular day. I also identify which countries are included in joint occurrence events. 


\subsection{Multinomial logit model}

Next step, I propose the multinomial logit model to investigate contagion within region and across regions. This approach allows us to capture the transmission channels through financial and economic relations, thereby provides policy makers with a complete understanding of various forms of contagion. Also, the model is able to predict the probability of the simultaneous occurrences of exceedances given the observed independent variables.

In my paper, the joint occurrences of exceedances are assumed to be the result of regional shocks. The model is given as follows:

$$
P_{k}=\frac{F\left(\beta_{0 k}+\beta_{1 k} \operatorname{Coexc}_{t-1}+\beta_{2 k} E X C_{t}+\beta_{3 k} \Delta I N T_{t}+\beta_{4 k} V O L_{t}\right)}{1+\sum_{i=1}^{k} F\left(\beta_{0 i}+\beta_{1 i} \operatorname{Coexc}_{t-1}+\beta_{2 i} E X C_{t}+\beta_{3 i} \Delta I N T_{t}+\beta_{4 i} V O L_{t}\right)},
$$

Normally, the multinomial logit regression model can be estimated in the form:

$$
P_{k}=\frac{\exp \left(\beta_{0 k}+\beta_{1 k} \operatorname{Coexc}_{t-1}+\beta_{2 k} E X C_{t}+\beta_{3 k} \Delta I N T_{t}+\beta_{4 k} V O L_{t}\right)}{1+\sum_{i=1}^{k} \exp \left(\beta_{0 i}+\beta_{1 i} \operatorname{Coexc}_{t-1}+\beta_{2 i} E X C_{t}+\beta_{3 i} \Delta I N T_{t}+\beta_{4 i} V O L_{t}\right)},
$$

where $\operatorname{Coexc}_{t-1}, E X C_{t}, \Delta I N T_{t}, V O L_{t}$ are the number of negative coexceedances at time $t-1$, the changes in exchange rates, the changes in regional short-term interest rates, the volatility of regional index, respectively;

$\beta$ is the vector of coefficients. Positive $\beta$ coefficients imply that an increase in covariates points at the higher probability of outcome $k$.

$k$ is the number of coexceedances at time $t$, and $k$ can take the integer value between 0 and 8. However, $k$ is categorized into five groups instead for $k=0,1,2,3$ and 4 , where $k=$ 4 encompasses the days with four or more coexceedances. Proceeding this way, the model is not only simpler and more parsimonious, but is able to capture the possible outcomes. Also, assigning $k$ to five categories gives more coexceedances for the model estimation since the large number of exceedances is less likely to occur jointly. If Greece, Spain experience extreme negative returns simultaneously in a given day, then $k=2$. Similarly, suppose that four or more stock market returns jointly exceed a pre-specified threshold, $k=$ 
4. If $k=8$, for an exogenous variable added to the model we have to estimate more eight parameters, thus it is hard to interpret the coefficients;

$P_{k}$ is the probability of observing $k$ coexceedances. In this model, $P_{k}$ always satisfies $0 \leq P_{k} \leq 1$, and $\sum_{k=0}^{4} P_{k}=1$.

Apart from OLS, the multinomial logit regression model is estimated by maximum likelihood for a sample of $n$ observations:

$$
\ln L=\sum_{l=1}^{n} \sum_{k=1}^{4} I_{l k} \ln P_{k}
$$

where $I_{l k}$ equals one if the $l$ th observation belongs to the $k$ th category, and zero otherwise.

For goodness-of-fit, I test the null hypothesis that all estimated coefficients are zero using Chi - Square test. The test compares the unrestricted model with the reduced one which only contains the intercept. For the linear regression, $R^{2}$ measures how accurate the model approximates the observed data. Contrarily, goodness-of-fit for the multinomial logit regression model is evaluated using the approach of McFadden (1974):

$$
\text { Pseudo }-R^{2}=1-\frac{\log L_{U}}{\log L_{R}}
$$

where $\log L_{U}$ is the maximum value of $\log$ likelihood function of the unrestricted (full) model, and $\log L_{R}$ is the maximum loglikelihood value of restricted model with the constant only. For discrete dependent variables, pseudo $-R^{2}$ increases as more covariates are included in the model and $0 \leq$ pseudo $-R^{2} \leq 1$.

However, global factors would probably contribute to coexceedance if the effects from global shocks dominate contagion effects. In line with Forbes (2012), I use a number of combinations of global shocks to control the common shocks: commodity price index changes, the changes in the U.S. long-term interest rates, the TED spread, and the VIX. Therefore, the full model is presented as follows:

$$
P_{k}=\frac{\exp \left(\beta_{k}^{\prime} x\right)}{1+\sum_{i=1}^{K} \exp \left(\beta_{i}^{\prime} x\right)}
$$


The case of no coexceedance is so-called the base category, and $\beta_{0}$ is normally set to zero for that category to ensure that the model is identified. The model is then represented in the form:

$$
P_{0}=\frac{1}{1+\sum_{i=1}^{K} \exp \left(\beta_{i}^{\prime} x\right)}
$$

where $x$ is the vector of covariates. Here I decompose the independent variables into idiosyncratic risks and common factors or global shocks. Examples of idiosyncratic risks are explanatory variables such as the number of negative coexceedances at time $t-1$ $\left(\operatorname{Coexc}_{t-1}\right)$, the changes in exchange rates $(E X C)$, the changes in regional short-term interest rates $(\triangle I N T)$, the volatility of regional index $(V O L)$. Global shocks are exogenous factors including commodity price index changes, the changes in the U.S. long-term interest rates, the TED spread, and the VIX.

The magnitude of the coefficients in the equation (6) is not intuitive to interpret, therefore I compute the marginal effects and test whether they are statistically significant different from zero. According to Cameron and Trivedi (2009), marginal effects disentangle the impacts of a given unit change in the regressors on the change in dependent variable. Specifically, in the multinomial logit regression model, the marginal effects are the changes in probability for a given unit change in the independent covariate. For the linear regression model, the marginal effects are simply measured by the slope coefficient. The nonlinear regression model, however, requires the marginal effects to be calculated by a different method. Following Greene (2000), and Bae et al. (2003), the marginal effects at the mean are computed as follows:

$$
\delta_{k}=\frac{\partial P_{k}}{\partial x_{k}}=P_{k}\left[\beta_{k}-\sum_{k=1}^{4} P_{k} \beta_{k}\right]=P_{k}\left[\beta_{k}-\bar{\beta}\right]
$$

The signs of the slopes in (6) and the signs of the marginal effect $\left(\delta_{k}\right)$ are not always the same. In fact, $\beta_{k}-\bar{\beta}$ determines the signs of $\delta_{k}$, if $\beta_{k}>\bar{\beta}, \delta_{k}$ is positive and negative otherwise. Since the marginal effects set all values of the explanatory variables to their unconditional mean, I propose to compute the predicted probability for each outcome to 
investigate how the changes in values of independent variables affect the conditional probability. Scott and Freese (2006) illustrates these probabilities visually by plotting a curve which is so - called "the coexceedance response cure"4

To investigate contagion from the Euro Area to Asia, I relate coexceedance to two more explanatory variables: the number of coexceedances and the stock market volatility of the Euro Area countries. The multinomial logit regression model is able to predict the probability of the simultaneous occurrences of exceedances in Asia given the simultaneous negative large returns in the Euro Area.

The coexceedance and the multinomial logit model are estimated using Matlab and SPSS, respectively. All code used in this paper are available for the interested readers.

\subsection{Exceedance estimation using Value-at-Risk}

For a robustness check, I instead employ Value-at-Risk approach that allows the evolution of threshold to estimate exceedance. To make the sign of VaR consistent with the traditional threshold, I set $\mathrm{VaR}$ to negative value. Using $\mathrm{VaR}$ origins from the fact that threshold is more likely to vary over time. I would apply historical simulation to estimate VaR. Exceedances are defined as the returns below VaR, thus exceedances are supposed to be time-varying.

$\mathrm{VaR}$ is defined as the smallest loss $l$ such that the probability of a future portfolio loss $L$ exceeding $l$ is less than or equal to $1-\alpha$. Mathematically, VaR is estimated in the following equation:

$$
\operatorname{VaR}_{\alpha}(L)=\inf \{l \in \mathbb{R}: \operatorname{Pr}(L>l) \leq 1-\alpha\}
$$

where inf denotes infimum. In this paper, $\alpha$ is set to be $5 \%$.

\footnotetext{
${ }^{4}$ Bae et al. (2003) first introduced this terminology.
} 
To estimate VaR, I apply a rolling window of size 500. That is, for each VaR estimation, I use 500 loss observations ahead. The rolling window can be illustrated visually in the following figure:

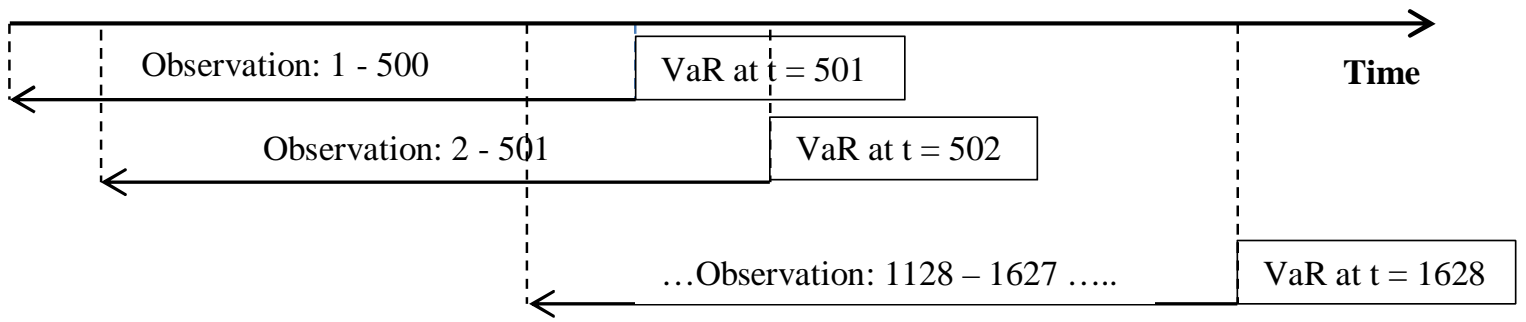

Figure 2: Rolling window of size 500 for VaR estimation

\section{Empirical Findings and Discussion}

\subsection{Coexceedance analysis}

Table 1 provides both the number of days and the percentage of sample period of (co)exceedances occurring in the Euro Area (Panel A) and Asian countries (Panel B). The number of coexceedances is categorized into five groups: $k=0,1,2,3$ and 4 . In the bottom line of each panel, I count the number of days for each group of coexccedances (e.g. there are 1341 days of no exceedances, equivalent to $82.37 \%$, in any stock market). There are 84 days with three or less Asian countries, but only 57 days for the Euro Area countries experiencing the large shocks. However, regarding four or more countries, the Euro Area is more likely to obtain negative exceedances than Asia, 94 days or $5.77 \%$ compared with 72 days or $4.36 \%$. In other words, there is more possibility for the Euro Area countries to have the bottom - tail return events simultaneously.

Also, I report a list of countries participating in each category of coexceedances to determine how regular those countries obtain negative extreme return. In the Euro Area, unexpectedly, a country participating in the negative return events most frequently is not the triggering country of the European Sovereign debt crisis (e.g. Greece, Portugal, Ireland etc.), but France with 88 of 94 days in the group of four or more coexceedances. Nevertheless, looking at the last column which shows the mean return of each stock market when four or more country gain extreme negative returns simultaneously, it is not surprise to conclude that Greece has the largest negative return and the average returns in the Euro 
Area is clearly greater than those in Asia. In Asia, Hong Kong involves in the category of above four joint - exceedances more regularly than other Asian countries (63 out of 71 days), but the stock market with the largest negative return is China.

Figure 3 exhibits the evolution of the number of coexceedances in the Euro Area and Asia between 02/01/2007 and 28/03/2013. There is substantial fluctuation in the occurrence of coexceedances over time. Four or more coexceedances mostly fall in the period of the end of 2008 to the beginning of 2009 and the end of 2011. In the global financial crisis, those coexceedances in Asia are observed to be more frequent than in the Europe Area, showing that a larger portion of Asian countries contain the bottom - tail returns. Figure 3 also provides expected evidence that the Euro Area stock markets are much more likely to experience negative exceedances simultaneously than the Asian ones in the European sovereign debt crisis. In other words, the Eurozone countries involve in extreme negative returns more regularly than Asia ones between the second half year of 2011 and the first half year of 2012. In fact, to confirm these observations, I count the number of days of coexceedances taking place in the period of the European sovereign debt crisis. The results are 43 days for the Euro Area and only 11 days for Asia.

\subsection{Contagion within the Euro Area and within Asia}

Perceiving the transmission channels of crisis is definitely the key demand of both investors and policymakers. Nevertheless, determining how crisis spreads across countries is not often certain and clear. In this section, I include the regional explanation variables into the multinomial logit model to investigate which channel is associated with the coincidence of exceedances. Those factors are considered as the idiosyncratic risks, namely the changes in short-term interest rates, the changes in exchange rates, and the market volatility. Subsequently, the commodity price index changes, the U.S. long-term interest rates changes, the TED spread, and the VIX are complemented to control for global shocks. 


\section{Table 1: Summary statistics of (co-exceedances) for daily stock market index returns in the Euro Area and Asia countries}

Panel A. Euro Area

\begin{tabular}{|c|c|c|c|c|c|c|c|c|c|c|c|}
\hline \multirow[t]{2}{*}{$k$} & \multicolumn{2}{|c|}{0} & \multicolumn{2}{|c|}{1} & \multicolumn{2}{|c|}{2} & \multicolumn{2}{|c|}{3} & \multicolumn{2}{|c|}{4} & \multirow{2}{*}{ Mean return when $\mathrm{k}=4$} \\
\hline & Days & $\%$ & Days & $\%$ & Days & $\%$ & Days & $\%$ & Days & $\%$ & \\
\hline GRE & 1341 & $82.37 \%$ & 49 & $3.01 \%$ & 13 & $0.80 \%$ & 5 & $0.31 \%$ & 44 & $2.70 \%$ & -0.0510 \\
\hline POR & 1341 & $82.37 \%$ & 25 & $1.54 \%$ & 15 & $0.92 \%$ & 12 & $0.74 \%$ & 69 & $4.24 \%$ & -0.0338 \\
\hline SPN & 1341 & $82.37 \%$ & 7 & $0.43 \%$ & 9 & $0.55 \%$ & 5 & $0.31 \%$ & 77 & $4.73 \%$ & -0.0289 \\
\hline FRA & 1341 & $82.37 \%$ & 2 & $0.12 \%$ & 4 & $0.25 \%$ & 11 & $0.68 \%$ & 88 & $5.41 \%$ & -0.0296 \\
\hline GER & 1341 & $82.37 \%$ & 8 & $0.49 \%$ & 3 & $0.18 \%$ & 4 & $0.25 \%$ & 74 & $4.55 \%$ & -0.0309 \\
\hline IRE & 1341 & $82.37 \%$ & 29 & $1.78 \%$ & 12 & $0.74 \%$ & 6 & $0.37 \%$ & 58 & $3.56 \%$ & -0.0329 \\
\hline NEL & 1341 & $82.37 \%$ & 10 & $0.61 \%$ & 7 & $0.43 \%$ & 7 & $0.43 \%$ & 78 & $4.79 \%$ & -0.0310 \\
\hline ITA & 1341 & $82.37 \%$ & 6 & $0.37 \%$ & 11 & $0.68 \%$ & 10 & $0.61 \%$ & 79 & $4.85 \%$ & -0.0301 \\
\hline Total & 1341 & $82.37 \%$ & 136 & $8.35 \%$ & 37 & $2.27 \%$ & 20 & $1.23 \%$ & 94 & $5.77 \%$ & -0.0335 \\
\hline
\end{tabular}

Panel B. Asia

\begin{tabular}{|c|c|c|c|c|c|c|c|c|c|c|c|}
\hline \multirow[t]{2}{*}{$k$} & \multicolumn{2}{|c|}{0} & \multicolumn{2}{|c|}{1} & \multicolumn{2}{|c|}{2} & \multicolumn{2}{|c|}{3} & \multicolumn{2}{|c|}{4} & \multirow[b]{2}{*}{ Mean return when $\mathrm{k}=4$} \\
\hline & Days & $\%$ & Days & $\%$ & Days & $\%$ & Days & $\%$ & Days & $\%$ & \\
\hline $\mathrm{CHN}$ & 1293 & $79.42 \%$ & 48 & $2.95 \%$ & 20 & $1.23 \%$ & 11 & $0.68 \%$ & 30 & $1.84 \%$ & -0.0446 \\
\hline HKG & 1293 & $79.42 \%$ & 8 & $0.49 \%$ & 7 & $0.43 \%$ & 17 & $1.04 \%$ & 63 & $3.87 \%$ & -0.0218 \\
\hline THL & 1293 & $79.42 \%$ & 28 & $1.72 \%$ & 12 & $0.74 \%$ & 13 & $0.80 \%$ & 38 & $2.33 \%$ & -0.0265 \\
\hline MAL & 1293 & $79.42 \%$ & 16 & $0.98 \%$ & 7 & $0.43 \%$ & 12 & $0.74 \%$ & 52 & $3.19 \%$ & -0.0240 \\
\hline SGP & 1293 & $79.42 \%$ & 14 & $0.86 \%$ & 12 & $0.74 \%$ & 17 & $1.04 \%$ & 57 & $3.50 \%$ & -0.0219 \\
\hline IND & 1293 & $79.42 \%$ & 23 & $1.41 \%$ & 17 & $1.04 \%$ & 10 & $0.61 \%$ & 51 & $3.13 \%$ & -0.0193 \\
\hline KOR & 1293 & $79.42 \%$ & 19 & $1.17 \%$ & 8 & $0.49 \%$ & 16 & $0.98 \%$ & 54 & $3.32 \%$ & -0.0229 \\
\hline JPN & 1293 & $79.42 \%$ & 24 & $1.47 \%$ & 11 & $0.68 \%$ & 15 & $0.92 \%$ & 48 & $2.95 \%$ & -0.0256 \\
\hline Total & 1293 & $79.42 \%$ & 180 & $11.06 \%$ & 47 & $2.89 \%$ & 37 & $2.27 \%$ & 71 & $4.36 \%$ & -0.0258 \\
\hline
\end{tabular}

The exceedances are defined as negative extreme returns that lie below the 5\% percentile (bottom tail) of the overall return distribution. Coexceedance is expressed as the coexistence of extreme values at a same point of time. The number of coexceedances is categorized into five groups: $k=0,1,2,3$ and 4 . A coexceedance of $k$ means that $k$ countries have an exceedance simultaneously. For example, of 1628 trading days, there are 94 days (5.77\%) more than 4 Eurozone countries experience negative exceedances on the same day, and 44 of those coexceedances include Greece as one of those countries. 


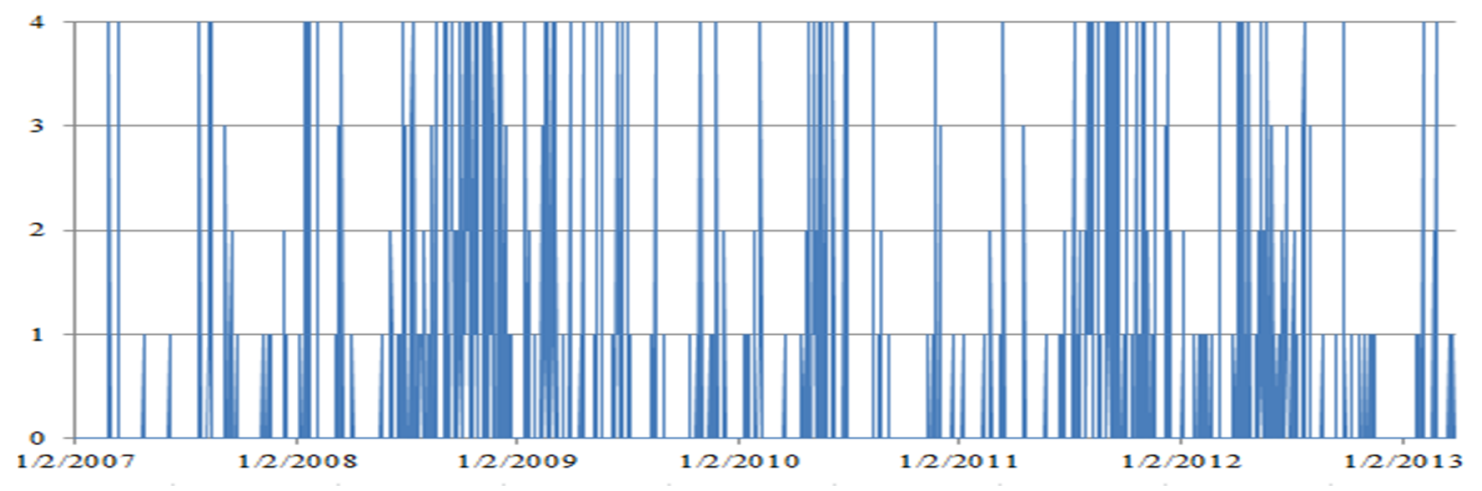

Panel A. Negative Coexceedance in the Euro Area

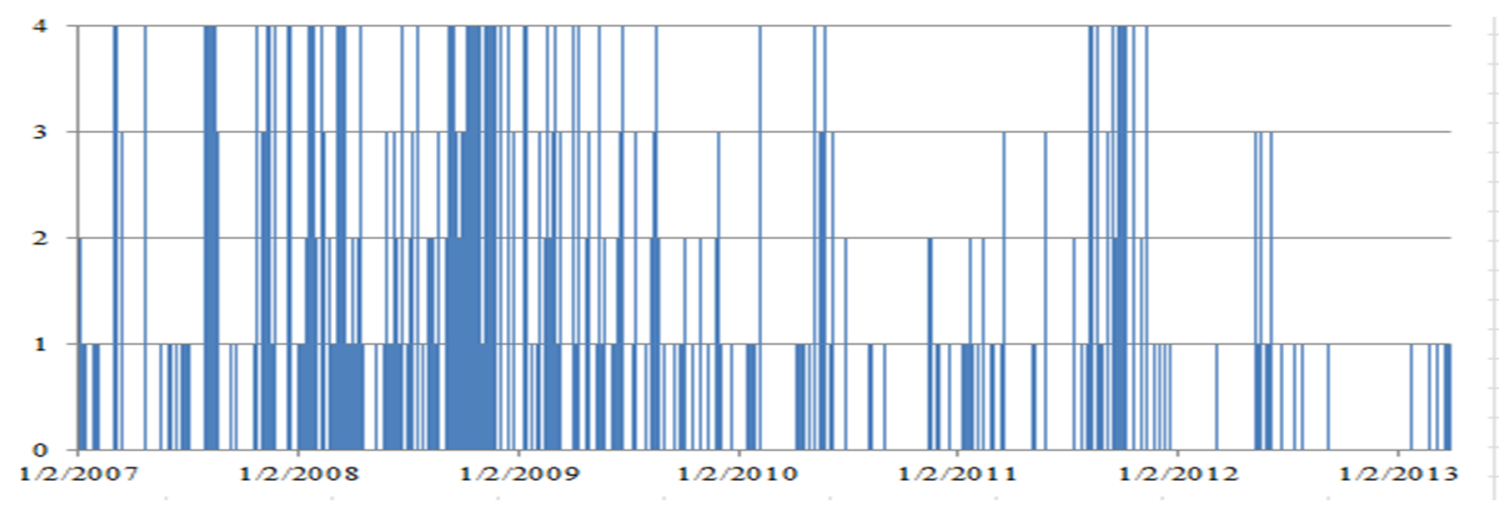

Panel B. Negative Coexceedance in Asia

Figure 3: Time Series Plot of the Negative Coexceedance in the Europe Area and Asia between 02/01/2007 and 28/03/2013.

This figure graphs the number of the negative coexceedance $(k)$ in the Europe Area and Asia, where $k=$ $0,1,2,3,4$.

\section{Idiosyncratic or regional shocks}

The estimation of multinomial logit model capturing the transmission channels of two recent crises in the Euro Area and Asia is given in Table 2. The left panel provides estimates for the Europe Area and the right panel reveals estimates for Asia. Under each model of the table, the column coeff. presents the parameter estimates, and the column $\Delta$ prob. reports the marginal effects.

Firstly, Model 1 investigates whether the joint-exceedances are autoregressive, i.e. I aim at testing if the number of coexceedances at time $t-1$ is able to predict the occurrence of coexceedances at time $t$. All coefficients are statistically significant and positive, implying the persistence effects which present same direction of successive returns. Accordingly, the 
more coexceedances occur yesterday, the more extreme negative returns are likely to be obtained simultaneously today. By adding different combinations of macro - finance variables: changes in short-term interest rates, changes of exchange rates, and market volatility to Model 2, the statistical significance of the lagged coexceedances is thinned down. The results show that volatility acts as expectation for both the Euro Area and Asia. All the coefficients are significant at the $1 \%$ level. Volatility has significant and positive impacts on the likelihood of the occurrence of coexceedances. Analyzing the degree of the volatility coefficients, I find the stronger effects of volatility on the probability of having a great number of coexceedances in the Euro Area. The results also indicate the weak significance of the changes in the regional short - term interest rates in the Euro Area, whereas the interest rate changes in Asia do not provide useful information to explain coexceedances. Interestingly, the currency movements are statistically significant for both the Euro Area and Asia. However, the effects of changes in exchange rates are not in the same direction. In particular, the changes in exchange rates are positively related to the likelihood of observing negative exceedances in the Euro Area, but negatively related to Asia's coexccedances. The more detailed discussion on this issue is presented when I analyze the coexceedance response curve.

To assess the goodness of fit involving the multinomial logit regression, I compare the value of $\log$ - likelihood and Pseudo- $R^{2}$ of two models and find those measures of Model 2 are higher than Model 1's. Furthermore, I apply Wald test to test if $E X C=\triangle I N T=$ $V O L=0$. Chi-square of 194.26 indicates the rejection of the null hypothesis. Therefore, all measures imply that the second model performs better than the first one.

As mentioned above, coexceedances may be caused by the global shocks rather than the regional factors. To control for such effects, I decide to include four global shocks, namely commodity price index changes, the change in the U.S. long-term interest rates, the TED spread, and the VIX. Model 3 illustrates the results of the regression with controls for global causes. This also enables to examine whether the probability of observing joint occurrences can be affected by the common factors. The magnitude of coefficients is not meaningful as it is often difficult to interpret the parameters in the multinomial logit model. Therefore, to analyze the impact of the macro - finance variables, I compute the marginal 
probability of coexceedances with respect to those covariates. After controlling for global shocks, there are some changes in the significance of the explanatory variables such as the lagged number of coexceedances and the regional short - term interest rates. Therefore, adding the common factors to the model is necessary.

I find the effects of coexceedances at time $t-1$ to diminish after pooling the regional and global covariates. For the Euro Area the signs of these coefficients are not consistent as the number of coexceedances increases. More specially, the lagged number of extreme negative returns raises the likelihood of observing two exceedances simultaneously today $\left(\beta_{12}=0.317\right)$, but reduces the likelihood of observing four or more coexceedances today $\left(\beta_{14}=-0.228\right)$. This implies that the "continuation" and "reversal" hypothesis are not supported in the Euro Area. In Asia, though the results indicate the "continuation" effect, the coefficients are only significant for the category of one and four or more coexceedances, whereas the results without controlling for global shocks are all significant at $10 \%$ level.

Looking at the coefficients of exchange rate changes, the response of the coexceedances' probability to exchange rate shocks is significant for all groups of coexceedances. Consistent with Model 2, the signs of the coefficients for the Euro Area and Asia are still opposite. In fact, a rise in USD/EUR raises the probability of coexceedances. But in Asia as the exchange rates increases on average, the joint negative extreme returns of the stock markets are less likely to happen. I apply the marginal effects to ascertain whether exchange rate shocks affect the likelihood of observing coexceedances. I find that the impact of changes in exchange rate is greater in Asia. Taking the category of four or more coexceedances as an example, a $1 \%$ increase in the USD/EUR exchange rates (i.e. depreciation of euro against dollar) significantly raises the probability of coexceedances in the Euro Area by $0.019 \%$, but a $1 \%$ depreciation of Asian currencies leads to the reduction of $0.075 \%$ in the likelihood of coexceedances in Asia.

Regarding the changes in the regional interest rates, I am unable to find their significance, implying that this variable is not of importance to predict the probability of coexceedances in the Euro Area and Asia. 
Table 2: Contagion test results of multinomial logit regression for daily negative coexceedances within the Euro Area and Asia in two cases: with and without controlling for global shocks.

\begin{tabular}{|c|c|c|c|c|c|c|c|c|}
\hline & \multicolumn{4}{|c|}{ Euro Area } & \multicolumn{4}{|c|}{ Asia } \\
\hline & \multirow{2}{*}{$\begin{array}{c}\text { Model } 1 \\
\text { Coeff. } \\
\end{array}$} & \multirow{2}{*}{$\begin{array}{c}\text { Model } 2 \\
\text { Coeff. }\end{array}$} & \multicolumn{2}{|c|}{ Model 3} & \multirow{2}{*}{$\begin{array}{c}\text { Model } 1 \\
\text { Coeff. } \\
\end{array}$} & \multirow{2}{*}{$\begin{array}{c}\text { Model } 2 \\
\text { Coeff. } \\
\end{array}$} & \multicolumn{2}{|c|}{ Model 3} \\
\hline & & & Coeff. & $\Delta$ prob. & & & Coeff. & $\Delta$ prob. \\
\hline \multicolumn{9}{|l|}{ Constant } \\
\hline$\beta_{01}$ & $-2.403^{*}$ & $-3.388^{*}$ & $-4.285^{*}$ & & $-2.091 *$ & $-3.016^{*}$ & $-2.982 *$ & \\
\hline$\beta_{02}$ & $-3.873^{*}$ & $-5.713 *$ & $-7.449 *$ & & $-3.460 *$ & $-4.862 *$ & $-4.923 *$ & \\
\hline$\beta_{03}$ & $-4.406^{*}$ & $-6.496^{*}$ & $-8.310^{*}$ & & $-3.787 *$ & $-5.835^{*}$ & $-5.958 *$ & \\
\hline$\beta_{04}$ & $-2.822 *$ & $-6.305^{*}$ & $-8.881 *$ & & $-3.245^{*}$ & $-5.902 *$ & $-6.100 *$ & \\
\hline \multicolumn{9}{|c|}{ Coexc $_{\mathrm{t}-1}$ : The number of coexceedances at $t-1$} \\
\hline$\beta_{11}$ & $0.250 *$ & $0.176^{* *}$ & 0.145 & 0.010 & $0.268 *$ & $0.209 *$ & $0.154 * * *$ & $0.013 * * *$ \\
\hline$\beta_{12}$ & $0.454 *$ & $0.283 * *$ & $0.317 * *$ & $0.004 * *$ & $0.308 * *$ & $0.229 * * *$ & 0.188 & 0.004 \\
\hline$\beta_{13}$ & $0.368 * *$ & 0.154 & -0.038 & -0.000 & $0.425^{*}$ & $0.270 * * *$ & 0.239 & 0.002 \\
\hline$\beta_{14}$ & $0.322 *$ & -0.004 & $-0.228 * * *$ & $-0.004 * * *$ & $0.537 *$ & $0.324 *$ & $0.246^{* *}$ & $0.004 * * *$ \\
\hline \multicolumn{9}{|c|}{ EXC: Changes in exchange rates } \\
\hline$\beta_{21}$ & & $0.852 *$ & $0.789 *$ & $0.055 *$ & & $-2.727 *$ & $-2.779 *$ & $-0.237 *$ \\
\hline$\beta_{22}$ & & $0.690 *$ & $0.673 *$ & $0.008^{*}$ & & $-4.083 *$ & $-4.216^{*}$ & $-0.081^{*}$ \\
\hline$\beta_{23}$ & & $0.672 * *$ & $0.630 *$ & $0.004 *$ & & $-4.442 *$ & $-4.864 *$ & $-0.047 *$ \\
\hline$\beta_{24}$ & & $1.506^{*}$ & $1.389^{*}$ & $0.019 *$ & & $-4.917^{*}$ & $-5.125^{*}$ & $-0.075^{*}$ \\
\hline \multicolumn{9}{|c|}{$\Delta I N T$ : Changes in the regional interest rates } \\
\hline$\beta_{31}$ & & 2.377 & 0.515 & 0.028 & & 1.193 & 1.271 & 0.115 \\
\hline$\beta_{32}$ & & $6.988 * * *$ & 3.643 & 0.048 & & 0.556 & 0.214 & 0.001 \\
\hline$\beta_{33}$ & & 3.605 & -0.048 & -0.001 & & 1.432 & 1.217 & 0.011 \\
\hline$\beta_{34}$ & & $6.095 * * *$ & 4.589 & 0.066 & & -0.496 & -0.505 & -0.011 \\
\hline \multicolumn{9}{|c|}{ VOL: Volatility of the regional stock markets } \\
\hline$\beta_{41}$ & & $0.034 *$ & $0.205 *$ & $0.014 *$ & & $0.033 *$ & $0.039 * *$ & $0.003 * *$ \\
\hline$\beta_{42}$ & & $0.065^{*}$ & $0.339 *$ & $0.004 *$ & & $0.043^{*}$ & 0.024 & 0.000 \\
\hline$\beta_{43}$ & & $0.073 *$ & $0.371 *$ & $0.002 *$ & & $0.061 *$ & $0.083 *$ & $0.001 *$ \\
\hline$\beta_{44}$ & & $0.103 *$ & $0.488 *$ & $0.007 *$ & & $0.0074 *$ & $0.063 *$ & $0.001 * *$ \\
\hline \multicolumn{9}{|c|}{$\Delta \mathrm{CPI}$ : Changes in the commodity price index } \\
\hline$\beta_{51}$ & & & $0.022 * *$ & $0.001 * * *$ & & & $-0.021 * *$ & $-0.002 * *$ \\
\hline$\beta_{52}$ & & & $0.049 *$ & $0.001 *$ & & & -0.001 & 0.000 \\
\hline$\beta_{53}$ & & & 0.015 & 0.000 & & & -0.013 & 0.000 \\
\hline$\beta_{54}$ & & & 0.010 & 0.000 & & & -0.013 & 0.000 \\
\hline
\end{tabular}


$\Delta$ USrate: Changes in the U.S. long - term interest rates

\begin{tabular}{|c|c|c|c|c|c|c|c|c|}
\hline$\beta_{61}$ & & & $-3.610 * *$ & $-0.241^{* *}$ & & & $-5.484 *$ & $-0.462 *$ \\
\hline$\beta_{62}$ & & & $-4.465 * *$ & -0.054 & & & $-7.968 *$ & $-0.151^{*}$ \\
\hline$\beta_{63}$ & & & $-10.888 *$ & $-0.072 *$ & & & $-13.638 *$ & $-0.135^{*}$ \\
\hline$\beta_{64}$ & & & $-8.641 *$ & $-0.119^{*}$ & & & $-11.804 *$ & $-0.175^{*}$ \\
\hline \multicolumn{9}{|c|}{ TED: TED Spread } \\
\hline$\beta_{71}$ & & & $0.008 *$ & $0.001 *$ & & & $0.006 *$ & $0.001 *$ \\
\hline$\beta_{72}$ & & & $0.017 *$ & $0.000 *$ & & & 0.006 & 0.000 \\
\hline$\beta_{73}$ & & & $0.015^{*}$ & $0.000 * *$ & & & $0.007 * * *$ & 0.000 \\
\hline$\beta_{74}$ & & & $0.013 *$ & $0.000 *$ & & & $0.006^{* *}$ & $0.000 * * *$ \\
\hline \multicolumn{9}{|l|}{ VIX } \\
\hline$\beta_{81}$ & & & $-0.180^{*}$ & $-0.012 *$ & & & -0.024 & -0.002 \\
\hline$\beta_{82}$ & & & $-0.301 *$ & $-0.004^{*}$ & & & 0.010 & 0.000 \\
\hline$\beta_{83}$ & & & $-0.318^{*}$ & $-0.002 *$ & & & -0.049 & -0.001 \\
\hline$\beta_{84}$ & & & $-0.390^{*}$ & $-0.005^{*}$ & & & -0.003 & 0.000 \\
\hline Log-likelihood & -1076.009 & -944.883 & -851.441 & & -1198.161 & -1057.938 & -1011.551 & \\
\hline Pseudo- $R^{2}$ & 0.016 & 0.136 & 0.222 & & 0.021 & 0.135 & 0.173 & \\
\hline
\end{tabular}

The table shows the results of the multinomial logit regression model for the negative exceedances for the Eurozone markets and the Asia markets. The multinomial logit regression model is in the form: $P_{k}=\frac{\exp \left(\beta_{k}^{\prime} x\right)}{1+\sum_{i=1}^{K} \exp \left(\beta_{i}^{\prime} x\right)}$. Model 1 measures the impacts of the lagged number of coexceedances. Model 2 measures the impacts of the regional macro-finance variables without global shocks. Model 3 controls for global shocks. The number of negative exceedances is modelled as the dependent variable in the multinomial logit regression model. The covariates, $x$, include the number of negative coexceedances at time $t-1\left(\operatorname{Coexc}_{t-1}\right)$, the changes in commodity price index $(\triangle C P I)$, the changes in the U.S. long-term interest rates $(\triangle U S r a t e)$, the TED spread (TED), VIX (VIX), the changes in exchange rates $(E X C)$, the changes in regional short-term interest rates $(\triangle I N T)$, the volatility of regional index $(V O L) . \beta_{0 i}$ are the intercept coefficients for each category $i$, where $i$ equals 1 to 4 . $\beta_{1 i}, \beta_{2 i}, \beta_{3 i}, \beta_{4 i}, \beta_{5 i}, \beta_{6 i}, \beta_{7 i}, \beta_{8 i}$ are the parameters of Count $_{t-1}, \triangle C P I, \triangle U$ Srate, TED, VIX, EXC, $\triangle I N T$, and VOL, respectively. *, **, and *** denote significance levels at the $1 \%, 5 \%$, and $10 \%$, respectively. 
In terms of the remaining regional variables, volatility appears to be useful to explain how coexceedances in both regions are affected. To identify the impact of volatility index, I analyze the magnitude of the marginal effects. As expectation, volatility has a positive correlation with the probability of observing exceedances. A $1 \%$ increase in stock markets' volatility would boost the likelihood of one exceedance and the likelihood of four or more coexccedances in the Euro Area by $0.014 \%$, and only $0.007 \%$, respectively. The corresponding figures for Asia are $0.003 \%$ and $0.001 \%$. The impacts of volatility index are stronger in the Euro Area stock markets.

\section{Global shocks}

Firstly I would like to address the question whether the commodity price index has significant impacts upon the probability of coexceedances. For the Euro Area, this regressor proposes only weak explanatory power for the categories of one and two extreme negative return(s), whereas in Asia the commodity price index provides no information for predicted probability of coexceedances. In contrast, it is interesting to note that the U.S. long - term interest rate changes have the most intensely impact upon the probability of observing coexceedances. In the Euro Area countries, an increase in the U.S long-term interest rates significantly reduces the probability of exceedances, and the effects even increase for higher number of coexceedances. As the U.S. 10-year Treasury bond rates increase, this might indicate the expectation of the global economy's recovery, coexceedances are less likely. In fact, a $1 \%$ increase in the long-term interest rates leads to a decrease of $0.119 \%$ in the probability of coexceedances. The interpretation should be understood with caution since the U.S. 10-year Treasury bond rate hardly fluctuates $1 \%$ in one day. Instead the basis point is commonly used to indicate the changes in interest rates. However, the results and the argument are similar. In addition, the magnitude of the marginal changes of probability of coexceedances in Asia is about double that in the Euro Area. I also include the TED spread as a variable for global shocks. The TED spread is measured as the difference between 3-month US Treasury Bill rate and 3-month LIBOR. The coefficients of this gap are positive and relevant as expectation in the Euro Area. Though the TED spread is significant at $1 \%$ level for all coexceedances, the impacts on the probability of observing the joint occurrences are negligible. This is confirmed in the results of the marginal effects. In Asia, the coefficients $\beta_{7 k}$ are significant for $k=1,3$, and 4 , but for the magnitude of the 
partial derivatives of the probability is significant for only one and four or more exceedances. This underpins the mathematical form of the nonlinear logistic map. In evaluating the impacts of VIX on probability of observing coexceedances, both the coefficients and the marginal effects are significant for all exceedance outcomes in the Euro Area. Surprisingly, the negative signs of VIX do not show as expectation. Again, I interpret this issue when analyzing the coexceedance response curve. In Asia the global volatility index is of no importance for the probability prediction, implying that Asia is more isolated from the effects of investors' sentiments than the Euro Area.

Comparing the results of three models, the log likelihood and Pseudo- $R^{2}$ are improved after both regional shocks and global factors are introduced. Model 3 achieves the highest value of $\log$ likelihood and Pseudo- $R^{2}$ with -851.441 , and 0.222 , respectively for the Euro Area; with -1011.551, and 0.173 for Asia. This indicates that including those variables enhances the quality of the model, thereby enriches the explanatory power of covariates to the predicted probability of coexceedances.

\section{Dynamic impacts of the regional and global shocks}

Since the marginal effects are computed as the partial derivatives of the probability of coexceedances with respective to the covariates at their unconditional mean, these values are constant irrespective of how the regressors vary over time. Therefore, if the probability is a nonlinear function of the explanatory variables, the partial derivatives provide incomplete view on the impacts of changes in the covariates. I plot the coexceedance response curve to better evaluate how the changes in the covariates determine the likelihood of joint occurrence of exceedances. Figure 4 exhibits the coexceedance response curve of negative extreme returns in the Euro Area and Asia. For the concise analysis, I only assess the effects of significant variables on the probability of coexceedances. The figure consists of three panels, in which Panel A illustrates the coexceedances response curves to the changes in exchange rates, Panel B for the volatility of stock returns, and Panel $\mathrm{C}$ for the lagged number of coexceedances. Except for the coexceedances response curves in Panel $\mathrm{C}$, all remaining plots provide clear evidences of nonlinear function of the probability. 
Starting with the case of the changes in exchange rates, if the exchange rates USD/EUR is unchanged, up to $90 \%$ no exceedances exist. However, if euro depreciates by $4 \%$, the probability of three or more coexceedances reaches around 50\%. As discussed earlier, the likelihood of joint extreme returns in Asia behaves differently with the changes in exchange rates. As the local currency is depreciated against dollar in the level of more than $1 \%$, coexceedances hardly occur. In contrast, average appreciations of $1 \%$ or more per day may lead the fact that $75 \%$ three or more stock markets experience negative extreme returns that day, and the higher the changes in exchange rates are, the weaker the currency markets affect the appearance of coexceedances. The opposite reactions of coexceedances in the Euro Area and Asia to the changes in exchange rates are probably interpreted as the considerable difference in monetary policy of European Central Bank (ECB) and central banks in Asian countries. The Euro Area has adopted a flexible exchange rate regime; hence the ECB only takes the effects of exchange rates into account when it carries out the monetary policy. The ECB makes no effort to stabilize the exchange rates. A depreciation of euro that may reflect a bleak outlook of the fundamental macroeconomic variables, therefore explain the higher probability of great number of exceedances. Contrarily, as export-based economies, a number of Asian countries, to some extent, apply monetory policy tools to intervene exchange rates (see Appendix 4 for the exchange rate regimes in the Euro Area and Asia). A weaker currency may benefit Asian exporters since their products become more competitive internationally. Take Japan as an example, the appreciation of $30 \%$ of Japanese yen led to a considerable decrease in export in the period of June 2007 and March 2009, especially for the automobile industry. During this period, the real export dropped $40 \%$ and the Nikkei 225 Index plummeted by $80 \%$. However, after the appointment of Japan's Prime Minister, Yoshihiko Noda, who supports more aggressive monetary stimulus, the yen began depreciating and the Nikkei 225 increased by $28 \%$ next three months. 

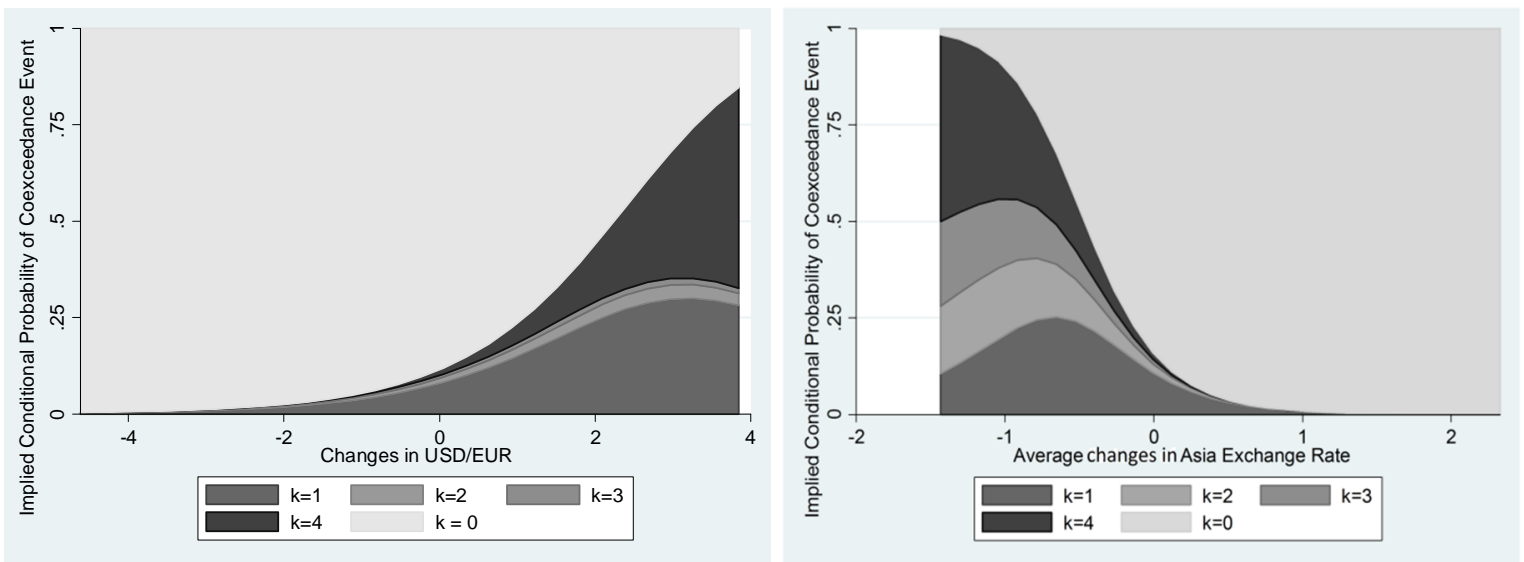

Panel A: Coexceedance response curve to the changes in exchanges rates.
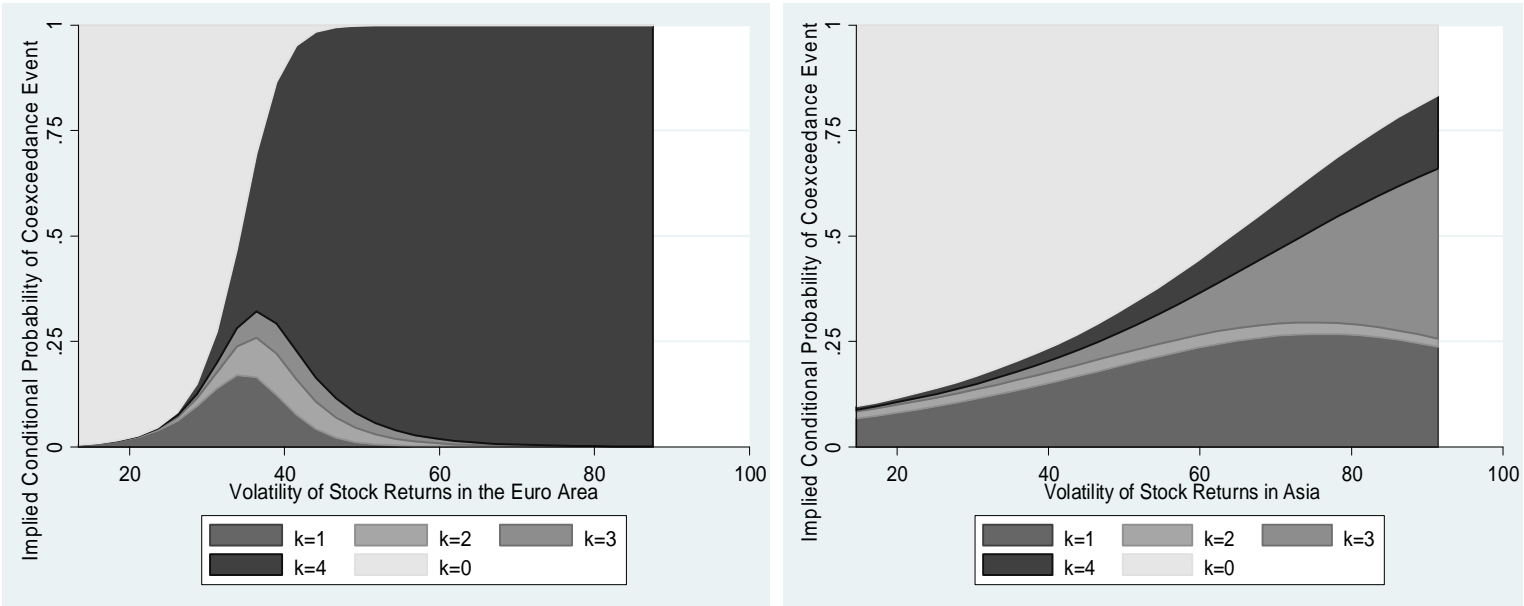

Panel B: Coexceedance response curve to the volatility of stock returns
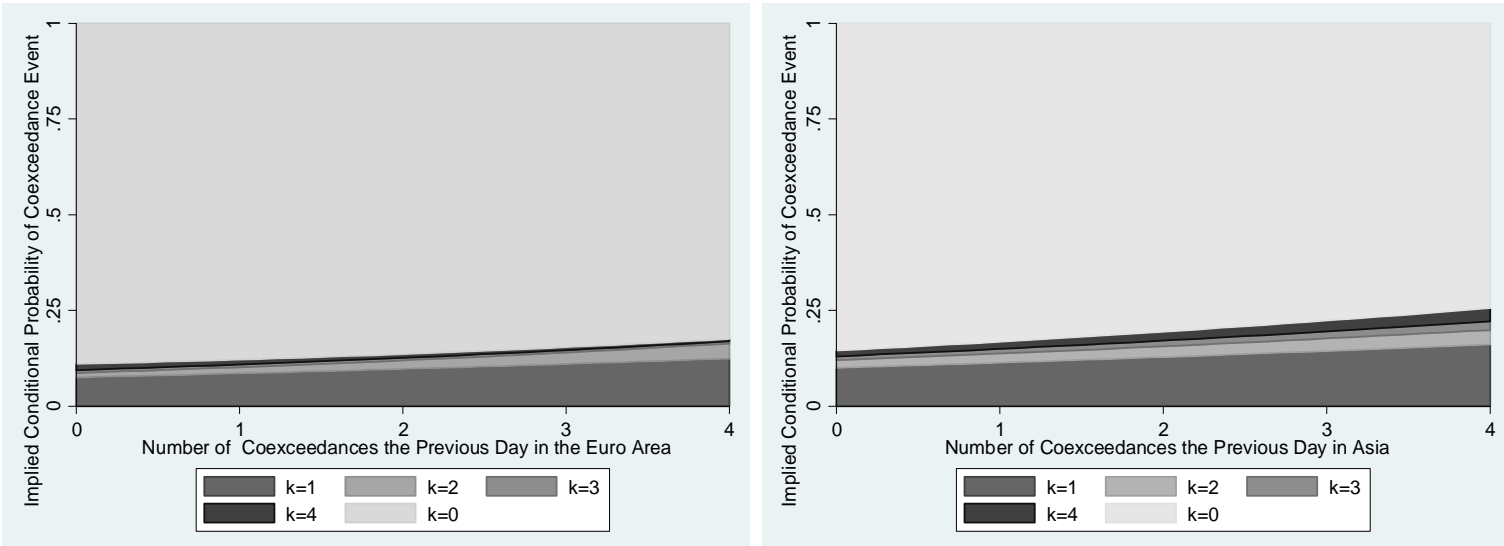

Panel C: Coexceedance response curve to the lagged number of coexceedances

Figure 4: Coexceedance response curves of negative extreme returns in the Euro Area and Asia 
Rodrik (2008) analyzing exchange rates of developing countries, for instance, points out that undervaluation of currency facilitates economic growth. As a result, a depreciation of currencies in Asia decreases the likelihood of coexceedances. These findings highlight that Eurozone countries are only able to minimize contagion effects by improving economic fundamentals, whereas the central banks in Asia could probably use exchange rate policy to mitigate contagion risks. However, a further study on the policy implications of exchange rates should be conducted with caution since currency devaluations can be costly and may engage in a currency war (Glick and Rose (1999)).

Now turning to the coexceedance response curve to the regional volatility of stock markets in Panel B, an obvious evidence of nonlinear curve can be seen in the Euro Area. In fact, the curve of coexceedances for $k=1,2$, and 3 looks like the bell shape. As the volatility index (VSTOXX) increases from 20 to below 40, the probability of various coexceedances rises significantly. But for the volatility index of above 40, the likelihood that less than three stock markets experience extreme negative returns declines and converges to zero when the volatility exceeds 60 . The probabilities of four or more coexceedances, conversely, rocket up for VSTOXX of above 40, indicating that the volatility index has powerful effect on predicting the probability of coexceedances. Asia's volatility index does not affect the probability as strong as the Euro Area's one. The likelihood of more than two coexceedances reaches maximum of $50 \%$ to $60 \%$ when the volatility index surpasses 60 .

The sensitive of coexceedances to the number of coexceedances for previous day in the Euro Area and Asia is similar. The response curve slope is nearly linear with the small magnitude, inferring that the impacts of the lagged number of extreme returns on the probability of coexceedances are relatively negligible for both regions.

Figure 5 illustrates the coexceedances response curves of the Euro Area and Asia to the investigated global shocks. In Panel A, the probabilities of coexceedances react in the same way in two areas. A decline in the U.S. long-term interest rates increases the likelihood of coexceedances nonlinearly. Since a reduction in the interest rates may represent a gloomy outlook of the global economy, it probably causes an increase in the possibility of the occurrence of exceedances. For instance, a decrease of $0.5 \%$ is likely to predict a $60 \%$ 
chance three or more coexceedances exist for the Euro Area and an $80 \%$ chance for Asia. Analyzing Panel B, the result is that when the TED spread become larger, the probability of various coexceedances is more likely. As the measurement of TED is more relevant in the Euro Area, the impacts of TED in the Euro Area are higher than in Asia. If the TED spread increases from 200 to 300, the likelihood of more than coexceedances increases from $10 \%$ to $60 \%$ in the Euro Area, but inconsiderably in Asia. The response of predicted probability is only significant and negative to VIX in the Euro Area. Apart from the regional volatility index, VIX - a measure of the investors' expectation on the U.S. stock market's uncertainty - has negative relation with the probability of coexceedances. When VIX exceeds 40, hardly do stock markets in the Euro Area achieve the extreme negative returns. A possible explanation of this finding is flight-to-quality. Once the U.S. stock market is expected to experience a highly volatile period, investors would shift their investment towards less riskier assets that could be European equities.

To conclude, this section addresses the question that whether there is the existence of contagion in the Euro Area and Asia in two recent crises. Comparing the value of Pseudo$R^{2}$ and the significance of covariates of Model 3 in the Euro Area and Asia, the conclusion inferred is that the unexplained fraction of extreme negative return events in Asia is greater than that in the Euro Area. In fact, Pseudo- $R^{2}$ of Model 3 in Asia is lower than that in the Euro Area, 0.173 compared with 0.222. Therefore, following the definition of contagion, contagion in Asia is much more important than in the Euro Area. 

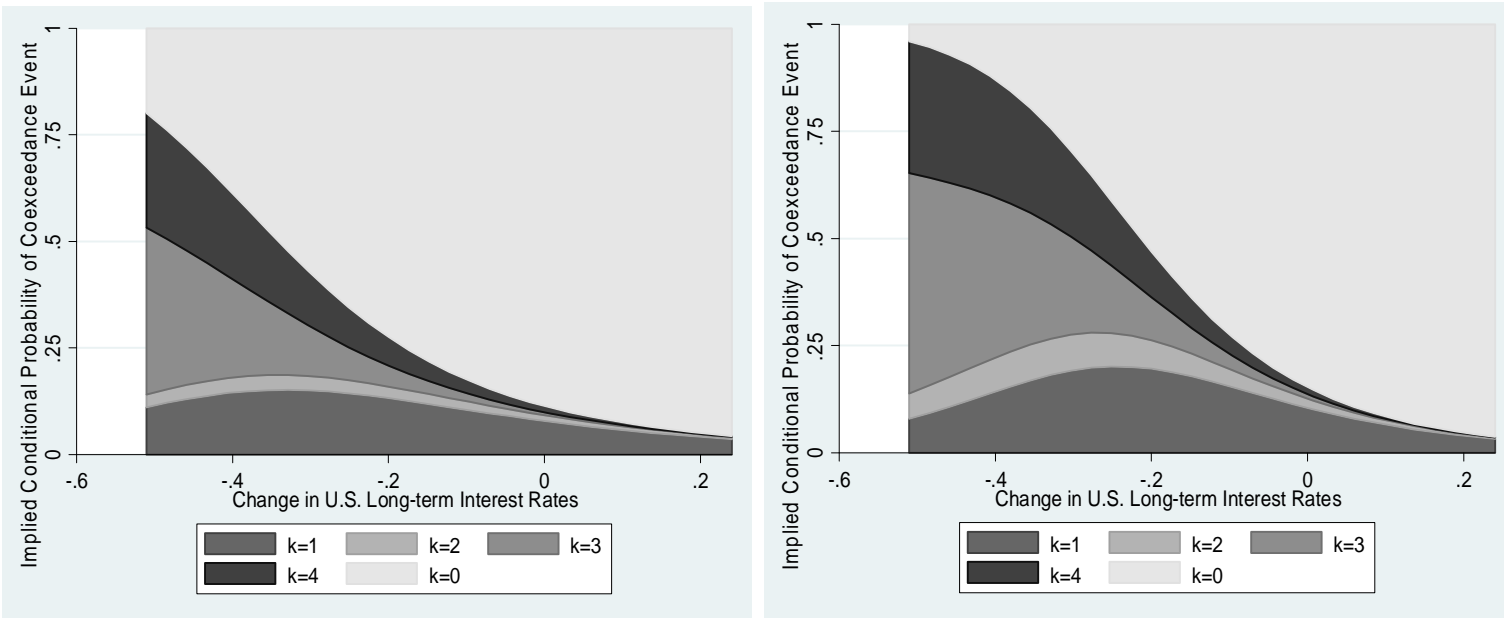

Panel A: Coexceedance response curve to the change in the U.S. long-term interest rates
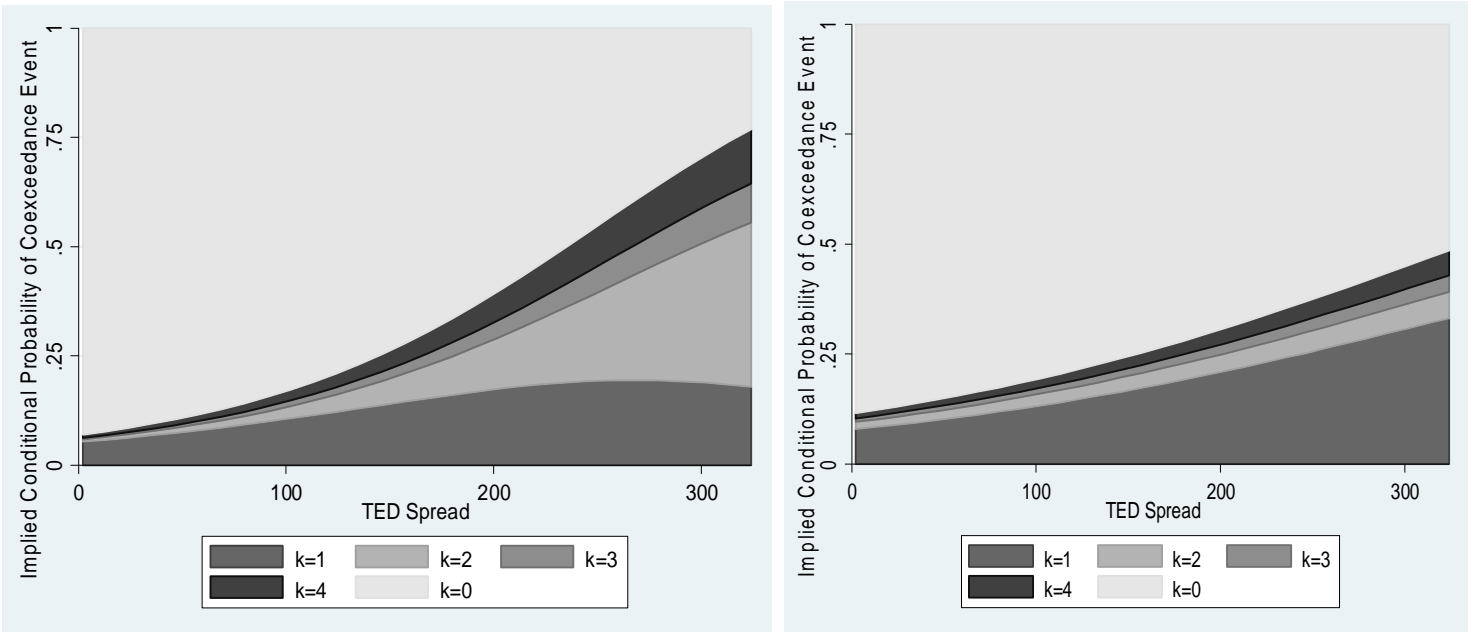

Panel B: Coexceedance response curve to the TED Spread

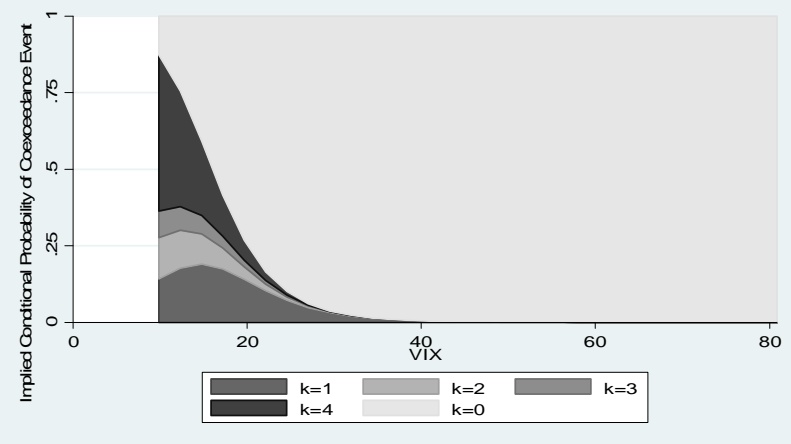

Panel C: Coexceedance response curve of the Euro Area to VIX

Figure 5: Coexceedance response curves of negative extreme returns in the Euro Area and Asia to global shocks 


\subsection{Contagion from the Euro Area to Asia}

This section examines contagion from the Euro Area to Asia. The evidence of contagion across regions would be found if the joint occurrences of exceedances in the Euro Area are significant in explaining the fraction of Asia coexceedances which is unexplained by its own macro-finance variables. I include more two covariates: the number of coexceedances and volatility index of the Euro Area, and apply the similar analysis framework used to investigate contagion within region.

The base model in Table 3 estimates the regression with two additional variables. The coefficients and the marginal effects are presented in the column coeff and column $\Delta$ prob, respecstively. The signs and significance of regression coefficients for old covariates are unaffected. Therefore, I only interpret the impacts of new variables. Neither the coefficients nor the marginal effects of volatility index of the Euro Area are significant to predict the occurrences of extreme negative returns. I re-estimate the model without the volatility index of the Euro Area stock markets, but the goodness-of-fit of the model and the results (not reported here) are similar. So I still use the volatility as a covariate to explore robustness tests.

The number of coexceedances in the Euro Area is significant and positive for all categories of coexceedances at $1 \%$ and $5 \%$ level. Accordingly, a rise in the number of exceedances in the Euro Area results in an increase in the probability of various coexceedance outcomes in Asia. This is possibly because during financial turmoil, due to the burden of extreme negative returns to meet the margin calls in the developed stock markets e.g. the Euro Area, investors are more inclined to short all risky assets, including the equities in the emerging countries, thereby depressing stock prices. Therefore, there exists contagion from the Euro Area to Asia. For further analysis, Figure 6 illustrates the impacts of the number of extreme returns in the Euro Area on the probability of coexceedances in Asia. Specifically, as the number of coexceedances in the Euro Area increases, the likelihood of observing high number of exceedances in Asia increases, which suggests that there exist the transmission of the exceedance shocks to Asia. Nevertheless, the effects hardly exceed $10 \%$. 
Table 3: Contagion test from the Euro Area to Asia, January 2, 2007, to March 28, 2013.

\begin{tabular}{|c|c|c|c|c|c|c|}
\hline \multirow[b]{3}{*}{ Constant } & \multicolumn{2}{|c|}{ Base Model } & \multicolumn{2}{|c|}{ Robustness Check $1^{5}$} & \multicolumn{2}{|c|}{ Robustness Check $2^{6}$} \\
\hline & Coeff. & $\Delta$ prob. & Coeff. & $\Delta$ prob. & Coeff. & $\Delta$ prob. \\
\hline & \multirow{2}{*}{\multicolumn{2}{|c|}{$-2.810^{*}$}} & \multirow{2}{*}{\multicolumn{2}{|c|}{$-2.955^{*}$}} & \multirow{2}{*}{\multicolumn{2}{|c|}{$-2.713^{*}$}} \\
\hline$\beta_{01}$ & & & & & & \\
\hline$\beta_{02}$ & \multicolumn{2}{|l|}{$-4.728^{*}$} & \multicolumn{2}{|l|}{$-5.048^{*}$} & \multicolumn{2}{|l|}{$-4.569^{*}$} \\
\hline$\beta_{03}$ & \multicolumn{2}{|l|}{$-6.198^{*}$} & \multicolumn{2}{|l|}{$-6.333^{*}$} & \multicolumn{2}{|l|}{$-5.920^{*}$} \\
\hline$\beta_{04}$ & \multicolumn{2}{|l|}{$-6.469 *$} & \multicolumn{2}{|l|}{$-6.776^{*}$} & \multicolumn{2}{|l|}{$-6.434 *$} \\
\hline \multicolumn{7}{|c|}{ Coexc $_{\mathrm{t}-1}$ : The number of coexceedances at $t-1$} \\
\hline$\beta_{11}$ & $0.152 * * *$ & $0.013 * * *$ & $0.140 * * *$ & 0.012 & $0.226^{*}$ & $0.020^{*}$ \\
\hline$\beta_{12}$ & 0.194 & 0.003 & 0.180 & 0.003 & $0.223 * * *$ & 0.004 \\
\hline$\beta_{13}$ & 0.232 & 0.002 & 0.216 & 0.002 & 0.172 & 0.001 \\
\hline$\beta_{14}$ & $0.244 * *$ & $0.003 * * *$ & $0.220 * * *$ & 0.003 & $0.329 *$ & $0.003 * *$ \\
\hline \multicolumn{7}{|c|}{$\Delta \mathrm{CPI}$ : Changes in the commodity price index } \\
\hline$\beta_{21}$ & $-0.022 * *$ & $-0.002 * *$ & $-0.019 * *$ & $-0.002 * *$ & -0.013 & -0.001 \\
\hline$\beta_{22}$ & -0.003 & 0.000 & -0.001 & 0.000 & -0.011 & -0.000 \\
\hline$\beta_{23}$ & -0.014 & 0.000 & -0.006 & 0.000 & -0.039 & -0.000 \\
\hline$\beta_{24}$ & -0.016 & 0.000 & -0.010 & 0.000 & -0.013 & -0.000 \\
\hline \multicolumn{7}{|c|}{$\Delta$ USrate: Changes in U.S. long - term interest rates } \\
\hline$\beta_{31}$ & $-5.180 *$ & $-0.446 *$ & $-5.042 *$ & $-0.426^{*}$ & $-6.104 *$ & $-0.546^{*}$ \\
\hline$\beta_{32}$ & $-6.957 *$ & $-0.122^{*}$ & $-7.019 *$ & $-0.117 *$ & $-6.121^{*}$ & $-0.135 * *$ \\
\hline$\beta_{33}$ & $-13.001 *$ & $-0.125^{*}$ & $-12.809 *$ & $-0.126^{*}$ & $-6.907 * * *$ & -0.033 \\
\hline$\beta_{34}$ & $-10.749 *$ & $-0.134 *$ & $-10.776^{*}$ & $-0.129 *$ & $-11.059 *$ & $-0.106^{*}$ \\
\hline \multicolumn{7}{|c|}{ TED: TED Spread } \\
\hline$\beta_{41}$ & $0.005^{* *}$ & $0.000 * *$ & $0.009^{*}$ & $0.001 *$ & $0.005^{*}$ & $0.001 * *$ \\
\hline$\beta_{42}$ & 0.005 & 0.000 & $0.009 * *$ & $0.000 * *$ & $0.010^{*}$ & $0.000 *$ \\
\hline$\beta_{43}$ & $0.008 * *$ & $0.000 * * *$ & $0.013 *$ & $0.000 *$ & $0.011 * *$ & 0.000 \\
\hline$\beta_{44}$ & $0.008 * *$ & $0.000 * *$ & $0.014 *$ & $0.000 *$ & 0.004 & 0.000 \\
\hline \multicolumn{7}{|l|}{ VIX } \\
\hline$\beta_{51}$ & -0.003 & 0.000 & $0.072 * *$ & $0.006 * *$ & $-0.099 *$ & $-0.009 *$ \\
\hline$\beta_{52}$ & 0.032 & 0.001 & $0.101 * * *$ & $0.002 * * *$ & $-0.086^{* * *}$ & -0.002 \\
\hline$\beta_{53}$ & -0.089 & -0.001 & 0.037 & 0.000 & -0.076 & -0.000 \\
\hline$\beta_{54}$ & -0.044 & -0.001 & 0.066 & 0.001 & $-0.091 * * *$ & -0.000 \\
\hline \multicolumn{7}{|c|}{ EXC: Changes in exchange rates } \\
\hline$\beta_{61}$ & $-2.761 *$ & $-0.241 *$ & $-2.665^{*}$ & $-0.229 *$ & $-3.234 *$ & $-0.288^{*}$ \\
\hline$\beta_{62}$ & $-4.055^{*}$ & $-0.072 *$ & $-3.943 *$ & $-0.067 *$ & $-3.973 *$ & $-0.091 *$ \\
\hline$\beta_{63}$ & $-4.642 *$ & $-0.043^{*}$ & $-4.397 *$ & $-0.042 *$ & $-4.248 *$ & $-0.021 *$ \\
\hline$\beta_{64}$ & $-4.736^{*}$ & $-0.058^{*}$ & $-4.524 *$ & $-0.053^{*}$ & $-4.911 *$ & $-0.046^{*}$ \\
\hline$\triangle I N T: \mathrm{Ch}$ & in the regi & al interest & & & & \\
\hline$\beta_{71}$ & 1.260 & 0.119 & 0.394 & 0.042 & 0.049 & 0.008 \\
\hline$\beta_{72}$ & 0.055 & -0.002 & -0.793 & -0.015 & -0.088 & -0.001 \\
\hline$\beta_{73}$ & 0.903 & 0.008 & -0.682 & -0.007 & -4.675 & -0.026 \\
\hline$\beta_{74}$ & -0.646 & -0.011 & -2.533 & -0.033 & -0.687 & -0.006 \\
\hline$V O L_{\text {Asia }}$ : & ility of Asia & stock mark & & & & \\
\hline$\beta_{81}$ & $0.040 * *$ & $0.004 * *$ & $-1.345^{*}$ & $-0.118^{*}$ & $0.045^{*}$ & $0.004 *$ \\
\hline$\beta_{82}$ & 0.028 & 0.000 & $-1.592 * *$ & $-0.027 * *$ & 0.042 & 0.001 \\
\hline$\beta_{83}$ & $0.087^{*}$ & $0.001 *$ & $-1.497 * *$ & $-0.014 * *$ & -0.015 & -0.000 \\
\hline$\beta_{84}$ & $0.069^{*}$ & $0.001 * *$ & $-1.617^{*}$ & $-0.018^{*}$ & $0.085^{*}$ & $0.000 *$ \\
\hline
\end{tabular}

${ }^{5}$ Standard deviation estimated by GARCH $(1,1)$ is considered as proxy of the volatility of Asian stock markets

${ }^{6}$ VaR estimation 


\begin{tabular}{|c|c|c|c|c|c|c|}
\hline \multicolumn{7}{|c|}{$\operatorname{Coexc}_{E U}$ : The number of coexceedances at $t-1$ in the Euro Area } \\
\hline$\gamma_{11}$ & $0.194 * *$ & $0.016 * * *$ & 0.139 & 0.011 & $0.289 *$ & $0.025^{*}$ \\
\hline$\gamma_{12}$ & $0.530^{*}$ & $0.010^{*}$ & $0.471 *$ & $0.008 *$ & $0.404 *$ & $0.009^{*}$ \\
\hline$\gamma_{13}$ & $0.366^{* *}$ & $0.003 *$ & $0.303 * *$ & $0.003 * * *$ & $0.569^{*}$ & $0.003 * *$ \\
\hline$\gamma_{14}$ & $0.569 *$ & $0.007 *$ & $0.500 *$ & $0.006^{*}$ & $0.827 *$ & $0.008 *$ \\
\hline \multicolumn{7}{|c|}{$V O L_{E U}:$ Volatility of the Euro Area stock markets } \\
\hline$\gamma_{21}$ & -0.027 & -0.003 & 0.009 & 0.001 & 0.041 & 0.003 \\
\hline$\gamma_{22}$ & -0.041 & -0.001 & 0.004 & 0.000 & 0.040 & 0.001 \\
\hline$\gamma_{23}$ & 0.029 & 0.000 & 0.073 & 0.001 & 0.077 & 0.000 \\
\hline$\gamma_{24}$ & 0.025 & 0.000 & $0.073 * * *$ & 0.001 & 0.037 & 0.000 \\
\hline $\begin{array}{l}\text { Log- } \\
\text { likelihood }\end{array}$ & -984.925 & & -982.456 & & -963.234 & \\
\hline Pseudo- $R^{2}$ & 0.195 & & 0.197 & & 0.207 & \\
\hline
\end{tabular}

The table shows the results of the multinomial logit regression model for the negative exceedances to test contagion from Euro Area to Asia. The multinomial logit regression model is in the form: $P_{k}=$ $\frac{\exp \left(\beta_{k}^{\prime} x\right)}{1+\sum_{i=1}^{K} \exp \left(\beta_{i}^{\prime} x\right)}$. The number of negative exceedances of Asian stock markets is modelled as the dependent variable in the multinomial logit regression model. The covariates, $x$, include the number of negative coexceedances of Asian stock markets at time $t-1\left(\mathrm{Coexc}_{t-1}\right)$, the change in commodity price index $(\triangle C P I)$, the change in the U.S. long-term interest rates ( $\triangle$ USrate), the TED spread (TED), the VIX (VIX), exchange rate return $(E X C)$, the changes in regional short-term interest rates $(\triangle I N T)$, the volatility of regional index $\left(V O L_{A s i a}\right) . \beta_{0 i}$ are the intercept coefficients for each category $i$, where $i$ equals 1 to $4 . \beta_{1 i}, \beta_{2 i}, \beta_{3 i}, \beta_{4 i}$, $\beta_{5 i}, \beta_{6 i}, \beta_{7 i}, \beta_{8 i}$ are the parameters of Count $_{t-1}, \triangle C P I, \Delta U S r a t e, T E D, V I X, E X C, \triangle I N T$, and VOL $L_{A s i a}$, respectively. Besides, two more independent variables are added: the number of negative coexceedances of Euro Area stock markets $\left(\operatorname{Count}_{E U}\right)$, and the volatility index of Euro Area stock markets $\left(V O L_{E U}\right) .{ }^{*}$, **, and $* * *$ denote significance levels at the $1 \%, 5 \%$, and $10 \%$, respectively.

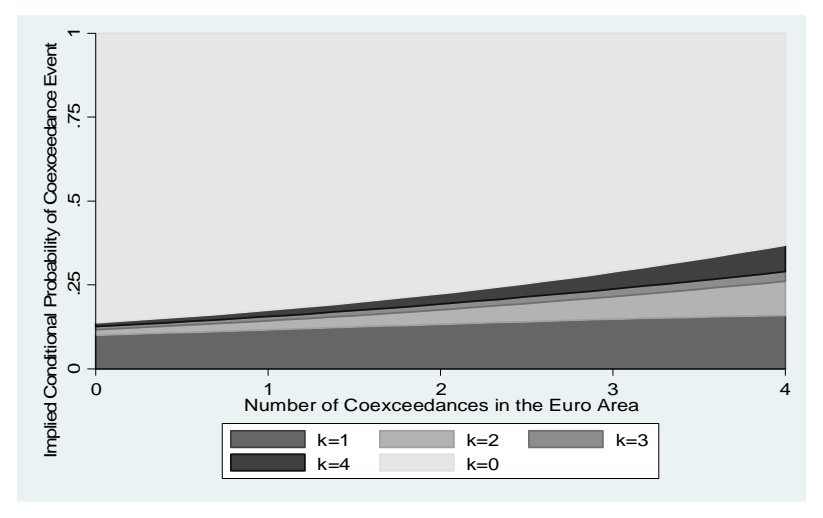

Figure 6: Coexceedance response curves of negative extreme returns in Asia to the number of coexceedances and the volatility of stock returns in the Euro Area 


\subsection{Robustness}

In this section, I run a battery of robustness checks in Table 3. Due to the unavailability of volatility of Asian stock markets, I apply the Japanese volatility index as a proxy of volatility index for the regional stock markets. Appendix 5 exhibits the volatility of U.S, the Euro Area, and Japanese stock markets. Tsunami disaster in March 2011 caused the plunge of Japanese stock market. The volatility index boosted sharply and dominated other indices this period. For robustness, therefore, now I estimate the model alternatively with the conditional volatility of Asia-Pacific stock markets. The conditional volatility is estimated as the square root of conditional variance of $\operatorname{GARCH}(1,1)$ of the form:

$$
\sigma_{t}^{2}=\alpha+\beta \sigma_{t-1}^{2}+\gamma \varepsilon_{t-1}^{2}
$$

where $\alpha>0, \beta$ and $\gamma \geq 0, \beta+\gamma<1$.

In the Robustness Check 1, generally, the results are not different from those of the base model. Though the signs of coefficients and the marginal effects now are not mixed, we still find no impacts of the volatility index of the Euro Area on predicting the probability of observing coexceedances in Asia. The number of coexceedances in Asia can be predicted by the corresponding exceedances in the Euro Area.

Finally, the alternative estimation of exceedances is implemented. Accordingly, exceedances are defined as negative returns below Value-at-Risk (VaR). In this section, $\mathrm{VaR}$ is computed using historical simulation. This approach permits exceedances to be time-varying rather than constant. I replicate all models whose results are provided in Appendix 6. Interestingly, this approach gives a similar pattern with the previous results with the exception of the regional stock market volatility in Asia. The Asian volatility index is only significant to explain the probability of the high number of coexceedances. In Table 3, the column Robustness check 2 reveals contagion test from the Euro Area to Asia. Still, the number of coexceedances in the Euro Area is useful to predict the probability of the joint exceedance occurrence whereas the volatility of the Euro Area stock markets is insignificant. 


\section{Conclusion}

My paper follows a coexceedance approach to examine financial contagion within and across regions in two recent episodes of financial markets. Given the argument that contagion is associated with negative events, I only focus on the occurrence of extreme negative returns (below 5\% percentile of unconditional return distribution). By applying the multinomial logit model to investigate the impacts of various macro-finance factors upon the probability of observing coexceedances, the paper achieves a number of clear findings.

Firstly, I find the presence of contagion within the Euro Area and within Asia. An important difference is that the investigated covariates are more significant in the Euro Area than Asia. That is, the macro-finance variables are more helpful to predict the likelihood of the occurrence of extreme negative returns in the Euro Area. Following the definition of contagion i.e. the fraction of negative coexceedance events that are not explained by the covariates included in the model, the paper provides clear evidence that contagion is more important in Asia than in the Euro Area.

After controlling for global shocks, I find various effects of macro-finance variables on the probability of coexceedances. The changes in exchange rates, the volatility of regional stock markets, the changes in the U.S. long-term interest rates, the TED spread, and VIX are strongly significant to explain the probability of the joint occurrences of heavy losses in the Euro Area. There are fewer factors intensely related to coexceedances' existence in Asia. Those variables are the changes in exchange rates, the volatility of regional stock markets, and the changes in the U.S. long-term interest rates. Despite different magnitude, most signs of coefficients and marginal effects for those variables are the same in two regions. Volatility of the regional stock markets and the TED spread have a positive relation with the probability of coexceedances, whereas an increase in changes in the U.S. long-term interest rates and VIX decreases the probability of the joint occurrences of exceedances. The changes in exchange rates, contrarily, affect the probability of observing coexceedances in different directions. On the one hand, the depreciation of euro boosts the chance coexceedances appear, on the other hand, the depreciation of Asian currencies considerably reduces the probability of observing coexceedances. 
Finally, although the volatility in the Euro Area is not significant to predict the probability of Asian coexceedances, I find the empirical evidence supporting the propagation of coexceedances in the Euro Area to Asia.

Contagion has been a great concern for both policy makers and investors. Understanding the transmission mechanism of crisis permits them to mitigate negative impacts of financial turmoil. My paper, however, only investigates the impacts of macro-finance variables with high frequency. Therefore, the findings could be further studied by assessing various channels such as leveraged banking system, foreign portfolio investment, public debt ratio, trade intensity and other macroeconomic fundamentals. However, the great challenge is that those variables are possibly sampled at different frequencies. In particular, financial data are often available for high frequency, whereas macroeconomic data are normally collected at lower frequency. A proposed approach is probably Mixed Data Sampling (MIDAS) regression models first introduced by Ghysels, Sinko, and Valkanov (2007). Furthermore, since exceedance estimation using VaR approach reveal a similar pattern with results investigated by the approach of Bae et al. (2003), a potential extension would be to estimate VaR with various approaches. 


\section{REFERENCES}

Bae, K. H., Karolyi, G. A. , \& Stulz, R. M. (2003). A new approach to measuring financial contagion. Review of Financial studies, 16(3), 717-763.

Baig, T., \& Goldfajn, I. (1998). Financial Market Contagion in the Asian Crisis (EPub): International Monetary Fund.

Baur, D.G. (2012). Financial contagion and the real economy. Journal of Banking and Finance, $36(10), 2680-2692$.

Bekaert, G., Ehrmann, M., Fratzscher, M., \& Mehl, A. J. (2011). Global crises and equity market contagion: National Bureau of Economic Research.

Bekaert, G., Harvey, C. R., \& Ng, A. (2005). Market Integration and Contagion. The Journal of Business, 78(1), 39-69.

Bernanke, B. S. (2013). Long-Term Interest Rates. from http://www.federalreserve.gov/newsevents/speech/bernanke20130301a.pdf

Billio, M., Duca, M. L., \& Pelizzon, L. (2003). The DCC test: powerless evidence of no contagion: Working paper.

Billio, M., \& Pelizzon, L. (2003). Contagion and interdependence in stock markets: Have they been misdiagnosed? Journal of Economics and Business, 55(5), 405-426.

Bordo, M. D., \& Murshid, A. P. (2000). Are financial crises becoming increasingly more contagious? What is the historical evidence on contagion? : National Bureau of Economic Research.

Boyer, B. H., Kumagai, T., \& Yuan, K. (2006). How Do Crises Spread? Evidence from Accessible and Inaccessible Stock Indices. Journal of Finance, 61(2), 957-1003.

Bussière, M., \& Fratzscher, M. (2006). Towards a new early warning system of financial crises. Journal of International Money and Finance, 25(6), 953-973.

Cameron, A. C., \& Trivedi, P. K. (2009). Microeconometrics using stata (Vol. 5): Stata Press College Station, TX.

Caporale, G. M., Cipollini, A., \& Spagnolo, N. (2005). Testing for contagion: a conditional correlation analysis. Journal of Empirical Finance, 12(3), 476-489.

Chiang, T.C., Jeon, B.N., \& Li, H. (2007). Dynamic correlation analysis of financial contagion: Evidence from Asian markets. Journal of International Money and Finance, 26(7), 12061228.

Cho, J. H., \& Parhizgari, A. M. (2008). East Asian financial contagion under DCC-GARCH. International Journal of Banking and Finance, 6(1), 2.

Christiansen, C., \& Ranaldo, A. (2009). Extreme coexceedances in new EU member states' stock markets. Journal of Banking \& Finance, 33(6), 1048-1057.

Ciarlone, A., \& Trebeschi, G. (2005). Designing an early warning system for debt crises. Emerging Markets Review, 6(4), 376-395.

Dornbusch, R., Park, Y. C., \& Claessens, S. (2001). Contagion: Why crises spread and how this can be stopped. International Financial Contagion. Claessens, S. and Forbes, K., Editors.

Norwell, MA: Kluwer Academic Publishers, 19-41.

Dungey, M., Fry, R., González-Hermosillo, B., \& Martin, V.L. (2005). Empirical modelling of contagion: a review of methodologies. Quantitative Finance, 5(1), 9-24.

Dungey, M., Fry, R., Martin, V., Tang, C., \& González-Hermosillo, B. (2010). Are financial crises alike? (Vol. 10): International Monetary Fund.

Dungey, M., \& Martin, V.L. (2007). Unravelling financial market linkages during crises. Journal of Applied Econometrics, 22(1), 89-119.

Essaadi, E., Jouini, J., \& Khallouli, W. (2009). The Asian crisis contagion: A dynamic correlation approach analysis. Panoeconomicus, 56(2), 241-260. 
Favero, C. A., \& Giavazzi, F. (2002). Is the international propagation of financial shocks nonlinear?: Evidence from the ERM. Journal of International Economics, 57(1), 231-246.

Forbes, K. J. (2012). The "Big C": Identifying Contagion: National Bureau of Economic Research.

Forbes, K. J., \& Rigobon, R. (2001). Measuring contagion: conceptual and empirical issues. International financial contagion, 43-66.

Forbes, K. J., \& Rigobon, R. (2002). No contagion, only interdependence: Measuring stock market comovements. Journal of Finance, 57(5), 2223-2261. doi: Doi 10.1111/0022-1082.00494

Ghysels, E., Sinko, A., \& Valkanov, R. (2007). MIDAS regressions: Further results and new directions. Econometric Reviews, 26(1), 53-90.

Glick, R., \& Rose, A. K. (1999). Contagion and trade: Why are currency crises regional? Journal of International Money and Finance, 18(4), 603-617.

Greene, W. H. (2000). Econometric Analysis. International Edition. Version IV), Prentice-Hall International Inc. New York University.

Ilzetzki, E., Reinhart, C., \& Rogoff, K. (2011). The Country Chronologies and Background Material to Exchange Rate Arrangements into the 21st Century: Will the Anchor Currency Hold: Working Paper.

Ismailescu, I., \& Kazemi, H. (2011). Contagion or Interdependence in Emerging Debt Markets? Banking and Finance Review, 3(2).

Kodres, L. E., \& Pritsker, M. (2002). A rational expectations model of financial contagion. The Journal of Finance, 57(2), 769-799.

Lin, C. M., \& Cheng, W. H. (2008). Economic determinants of comovement across international stock markets: the example of Taiwan and its key trading partners. Applied Economics, 40(9), 1187-1205.

Liu, L. (2011). Extreme-Downside-Risk Spillover from the United States and Japan to AsianPacific Stock Markets. Available at SSRN 1852592.

McFadden, D. (1974). The measurement of urban travel demand. Journal of public economics, 3(4), 303-328.

McGuire, P., \& Schrijvers, M. (2003). Common factors in emerging market spreads. BIS Quarterly Review, December.

Metiu, N. (2011). Financial contagion in developed sovereign bond markets: METEOR, Maastricht Research School of Economics of Technology and Organizations.

Missio, S., \& Watzka, S. (2011). Financial contagion and the European debt crisis: CESifo working paper: Monetary Policy and International Finance.

Naoui, K., Liouane, N., \& Brahim, S. (2010). A dynamic conditional correlation analysis of financial contagion: The case of the subprime credit crisis. International Journal of Economics and Finance, 2(3), 85-96.

Remolona, E., Scatigna, M., \& Wu, E. (2007). Interpreting sovereign spreads. BIS Quarterly Review, March.

Rodrik, D. (2008). The real exchange rate and economic growth. Brookings Papers on Economic Activity, 2008(2), 365-412.

Scott, L. J., \& Freese, J. (2006). Regression models for categorical dependent variables using Stata.

Syllignakis, M. N., \& Kouretas, G. P. (2011). Dynamic correlation analysis of financial contagion: Evidence from the Central and Eastern European markets. International Review of Economics \& Finance, 20(4), 717-732.

Thomadakis, A. (2012). Measuring Financial Contagion with Extreme Coexceedances. 


\section{APPENDICES}

\section{Appendix 1: Information Variable Specification}

\begin{tabular}{|c|c|c|}
\hline Indices & Description & Code \\
\hline $\begin{array}{ll}\text { Stock } & \text { market } \\
\text { indices }\end{array}$ & $\begin{array}{l}\text { Greece: Athex Composite, Portugal: PSI 20, Spain: IBEX } 35 \text {, } \\
\text { Germany: DAX 30, Ireland: ISEQ, the Netherlands: AEX, Italy: } \\
\text { Area: Euro Stoxx, China: Shanghai SE Composite, Hong Kong: Ha } \\
\text { Thailand: Bangkok SET, Malaysia: FBMKLCI, Indonesia: IDX Co } \\
\text { MSCI Singapore, Korea: Kospi, Japan: Nikkei 225, Asia-Pacific: } \\
600\end{array}$ & $\begin{array}{l}\text { France: CAC 40, } \\
\text { SE MIB, the Euro } \\
\text { g Seng Composite, } \\
\text { nposite, Singapore: } \\
\text { TOXX Asia/Pacific }\end{array}$ \\
\hline $\begin{array}{l}\text { Commodity price } \\
\text { index }\end{array}$ & $\begin{array}{l}\text { Commodity prices are measured by S\&P GSCI, which serves as } \\
\text { benchmark index in the commodity market and as a measure the } \\
\text { performance of commodity over time }\end{array}$ & CGSYSPT(PI) \\
\hline $\begin{array}{l}\text { U.S. long-term } \\
\text { interest rates }\end{array}$ & $\begin{array}{l}\text { 10-year constant maturity government bond rate describes an } \\
\text { average yield on the U.S. Treasury bond adjusted to a constant } \\
\text { maturity of } 10 \text { years. }\end{array}$ & FRTCM10(IR) \\
\hline TED Spread & $\begin{array}{l}\text { The TED Spread is the difference between 3-month US Treasury } \\
\text { Bill rate and 3-month LIBOR }\end{array}$ & TRTEDSP \\
\hline VIX & $\begin{array}{l}\text { VIX - Chicago Board Options Exchange Market Volatility Index } \\
\text { measures the implied volatility of S\&P } 500 \text { options. VIX represents } \\
\text { a measure of market expectations of short-term volatility and could } \\
\text { be considered as investors' sentiments }\end{array}$ & CBOEVIX \\
\hline Exchange rates & $\begin{array}{l}\text { USD/EUR (the units of euro to exchange for one dollar), } \\
\text { USD/CNY, USD/HKD, USD/THB, USD/MYR, USD/ SGD, } \\
\text { USD/IDR, USD/KRW, USD/JPY }\end{array}$ & \\
\hline $\begin{array}{l}\text { Regional short- } \\
\text { term interest rates }\end{array}$ & $\begin{array}{l}\text { 1-month EURIBOR (Euro Inter Bank Offered Rate) serves as the } \\
\text { base rate for a substantial number of financial products. It plays an } \\
\text { important role in the short-term loans in euro. 1-month SIBOR } \\
\text { (Singapore Inter Bank Offered Rate) is an important benchmark } \\
\text { used commonly in Asia. }\end{array}$ & $\begin{array}{l}\text { EIBOR1M, } \\
\text { SGSIB1M }\end{array}$ \\
\hline $\begin{array}{l}\text { Volatility of the } \\
\text { regional stock } \\
\text { markets }\end{array}$ & $\begin{array}{l}\text { The VSTOXX Indices indicate the expectation of the stock market } \\
\text { volatility in the Euro Area (Euro Stoxx). It is computed as the } \\
\text { square root of the implied variance of all Euro Stoxx options. The } \\
\text { Nikkei Stock Average Volatility Index measures the expectation of } \\
\text { future volatility of the Japanese stock market. }\end{array}$ & $\begin{array}{l}\text { VSTOXXI, } \\
\text { VXJINDX }\end{array}$ \\
\hline
\end{tabular}

Sources: Datastream, Morningstar, INC., Stoxx Limited, S\&P Dow Jones Indices LLC. 


\section{Appendix 2: Descriptive statistics}

Panel A: Statistics summary

\begin{tabular}{lllllllllllllllll}
\hline GRE & POR & SPN & FRA & GER & IRE & NEL & ITA & CHN & HKG & THL & MAL & SGP & IND & KOR & JPN \\
\hline
\end{tabular}

\begin{tabular}{|c|c|c|c|c|c|c|c|c|c|c|c|c|c|c|c|c|}
\hline Mean & 0.001 & 0.000 & 0.000 & 0.000 & 0.000 & 0.001 & 0.000 & 0.001 & 0.000 & 0.000 & 0.001 & 0.000 & 0.000 & 0.001 & 0.000 & 0.000 \\
\hline Median & 0.000 & 0.000 & 0.000 & 0.000 & 0.000 & 0.000 & 0.000 & 0.000 & 0.000 & 0.000 & 0.000 & 0.000 & 0.000 & 0.001 & 0.000 & 0.000 \\
\hline $\begin{array}{l}\text { Mode } \\
\text { Standard }\end{array}$ & 000 & 0.000 & 0.000 & 0.000 & 0.000 & 0.000 & 0.000 & 0.000 & 000 & 000 & 0.000 & 0.000 & .000 & .000 & .000 & .000 \\
\hline Deviation & 0.021 & 0.014 & 0.018 & 0.017 & 0.016 & 0.018 & 0.016 & 0.018 & 0.018 & 0.018 & 0.014 & 0.009 & 0.014 & 0.015 & 0.015 & 0.015 \\
\hline Kurtosis & 2.921 & 7.045 & 5.217 & 5.372 & 5.963 & 5.405 & 7.181 & 3.932 & 3.300 & 6.124 & 7.241 & 14.73 & 4.867 & 7.552 & 7.398 & 8.215 \\
\hline Skewness & 0.099 & 0.050 & 0.203 & 0.114 & 0.103 & 0.452 & 0.130 & 0.013 & 0.365 & 0.003 & 0.690 & 1.316 & 0.156 & 0.680 & 0.563 & 0.368 \\
\hline & - & - & - & - & - & - & - & - & - & - & - & - & - & - & - & - \\
\hline Minimum & 0.102 & 0.104 & 0.096 & 0.095 & 0.074 & 0.140 & 0.096 & 0.086 & 0.093 & 0.122 & 0.111 & 0.100 & 0.087 & 0.110 & 0.112 & 0.100 \\
\hline Maximum & 0.134 & 0.102 & 0.135 & 0.106 & 0.108 & 0.097 & 0.100 & 0.109 & 0.090 & 0.118 & 0.075 & 0.043 & 0.075 & 0.076 & 0.113 & 0.129 \\
\hline
\end{tabular}


Panel B: Correlations

\begin{tabular}{|c|c|c|c|c|c|c|c|c|}
\hline Euro Area & GRE & POR & SPN & FRA & GER & IRE & NEL & ITA \\
\hline GRE & 1 & & & & & & & \\
\hline POR & 0.534 & 1 & & & & & & \\
\hline SPN & 0.515 & 0.790 & 1 & & & & & \\
\hline FRA & 0.521 & 0.781 & 0.891 & 1 & & & & \\
\hline GER & 0.499 & 0.722 & 0.822 & 0.927 & 1 & & & \\
\hline IRE & 0.474 & 0.631 & 0.669 & 0.734 & 0.679 & 1 & & \\
\hline NEL & 0.519 & 0.748 & 0.832 & 0.942 & 0.893 & 0.741 & 1 & \\
\hline ITA & 0.512 & 0.773 & 0.893 & 0.915 & 0.856 & 0.670 & 0.863 & 1 \\
\hline Asia & $\mathrm{CHN}$ & $\mathrm{HKG}$ & THL & MAL & SGP & IND & KOR & JPN \\
\hline $\mathrm{CHN}$ & 1 & & & & & & & \\
\hline HKG & 0.501 & 1 & & & & & & \\
\hline THL & 0.249 & 0.589 & 1 & & & & & \\
\hline MAL & 0.299 & 0.545 & 0.455 & 1 & & & & \\
\hline SGP & 0.340 & 0.768 & 0.590 & 0.589 & 1 & & & \\
\hline IND & 0.291 & 0.633 & 0.541 & 0.562 & 0.643 & 1 & & \\
\hline KOR & 0.344 & 0.697 & 0.484 & 0.518 & 0.659 & 0.535 & 1 & \\
\hline JPN & 0.294 & 0.624 & 0.422 & 0.455 & 0.563 & 0.471 & 0.639 & 1 \\
\hline
\end{tabular}

Appendix 3: The number of days of (co)exceedances

\begin{tabular}{rccccc}
\hline & \multicolumn{3}{c}{ Euro Area } & & \multicolumn{2}{c}{ Asia } \\
\cline { 2 - 3 } \cline { 5 - 6 } \cline { 5 - 6 } & $(1)$ & $(2)$ & & $(3)$ & $(4)$ \\
1 & 1341 & $82.37 \%$ & & 1293 & $79.42 \%$ \\
2 & 136 & $8.35 \%$ & & 180 & $11.06 \%$ \\
3 & 20 & $2.27 \%$ & & 47 & $2.89 \%$ \\
$>=4$ & 94 & $1.23 \%$ & & 37 & $2.27 \%$ \\
\hline
\end{tabular}

The exceedances are defined as negative extreme returns that lie below the 5\% percentile (bottom tail) of the overall return distribution. Coexceedance is expressed as the coexistence of extreme values at a same point of time. The number of coexceedances is categorized into five groups: $k=0,1,2,3$ and 4 . A coexceedance of $k$ means that $k$ countries have an exceedance simultaneously. 
Appendix 4: Exchange rate regimes in the Euro Area and 8 Asia countries

\begin{tabular}{ccll}
\hline Country & Currency & Exchange rate regime & \multicolumn{1}{c}{ Comments } \\
\hline Euro Area & Euro & Freely floating & \\
China & Renminbi & De facto peg to US dollar & \\
Hong Kong & Hong Kong dollar & Peg to US dollar \\
Thailand & Thai Baht & De facto moving band & $+/-2 \%$ band \\
& & around US dollar & \\
Malaysia & Malaysian Ringgit & De facto moving band & $+/-2 \%$ band. Officially it is a managed \\
& & around the US dollar & float against an undisclosed basket of \\
& & currencies. \\
Singapore & Singapore Dollar & De facto moving band & $+/-2 \%$ band. Officially adjusted on the \\
& & around the US dollar & basis of a basket of currencies. \\
Indonesia & Indonesian Rupiah & Managed & $+/-5 \%$ band. \\
& & crawling band & \\
& & around US dollar & \\
Korea & South Korean won & Managed floating & \\
Japan & Japanese yen & Freely floating &
\end{tabular}

Source: European Central Bank, Ilzetzki, Reinhart, and Rogoff (2011)

\section{Appendix 5: Volatility of the U.S., the Euro Area, Asian stock markets}

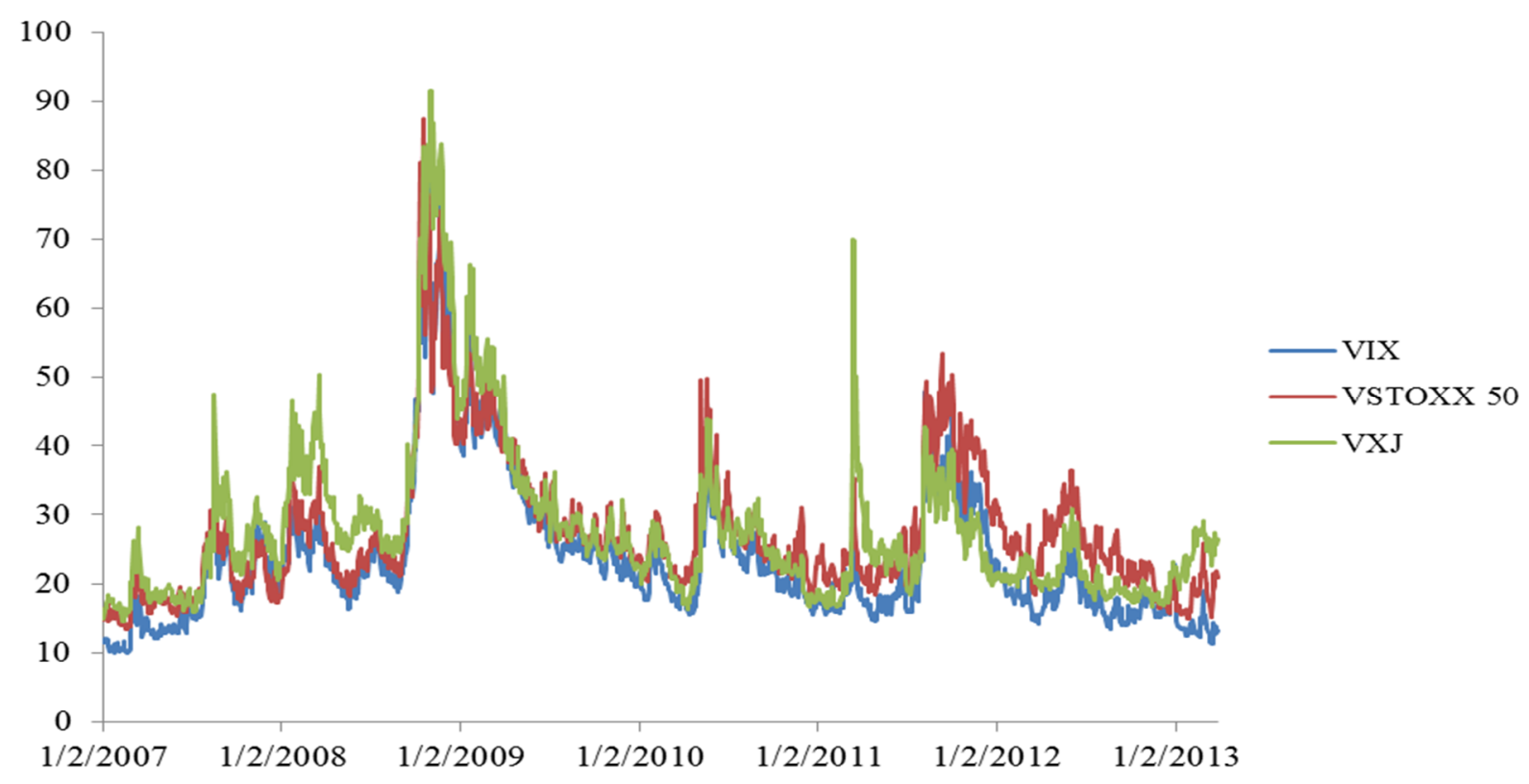




\section{Appendix 6: Contagion test within the Euro Area and Asia using VaR to estimate exceedances}

\begin{tabular}{|c|c|c|}
\hline & $\begin{array}{c}\text { Euro Area } \\
\text { Coeff. }\end{array}$ & $\begin{array}{c}\text { Asia } \\
\text { Coeff. }\end{array}$ \\
\hline Constant & & \\
\hline Constant & & \\
\hline$\beta_{01}$ & $-3.562 *$ & $-2.394 *$ \\
\hline$\beta_{02}$ & $-4.574 *$ & $-4.205^{*}$ \\
\hline$\beta_{03}$ & $-6.372^{*}$ & $-5.158^{*}$ \\
\hline$\beta_{04}$ & $-6.510^{*}$ & $-5.473^{*}$ \\
\hline \multicolumn{3}{|c|}{$\operatorname{Coexc}_{\mathrm{t}-1}$ : The number of coexceedances at $t-1$} \\
\hline$\beta_{11}$ & $0.275^{*}$ & $0.255^{*}$ \\
\hline$\beta_{12}$ & $0.399 *$ & $0.256^{* *}$ \\
\hline$\beta_{13}$ & 0.058 & 0.221 \\
\hline$\beta_{14}$ & 0.047 & $0.421 *$ \\
\hline \multicolumn{3}{|c|}{$\Delta$ CPI: Changes in the commodity price index } \\
\hline$\beta_{21}$ & 0.010 & -0.012 \\
\hline$\beta_{22}$ & $0.025 * * *$ & -0.009 \\
\hline$\beta_{23}$ & 0.016 & -0.034 \\
\hline$\beta_{24}$ & 0.017 & -0.002 \\
\hline \multicolumn{3}{|c|}{$\Delta$ USrate: Changes in the U.S. long - term interest rates } \\
\hline$\beta_{31}$ & $-4.672 *$ & $-6.409^{*}$ \\
\hline$\beta_{32}$ & $-4.548 * *$ & $-6.513 *$ \\
\hline$\beta_{33}$ & -3.318 & $-7.615^{* *}$ \\
\hline$\beta_{34}$ & $-7.315^{*}$ & $-12.672 *$ \\
\hline \multicolumn{3}{|l|}{ TED: TED Spread } \\
\hline$\beta_{41}$ & $0.012 *$ & $0.006^{*}$ \\
\hline$\beta_{42}$ & $0.013 *$ & $0.010^{*}$ \\
\hline$\beta_{43}$ & $0.018^{*}$ & $0.010^{* *}$ \\
\hline$\beta_{44}$ & $0.023 *$ & 0.005 \\
\hline \multicolumn{3}{|l|}{ VIX } \\
\hline$\beta_{51}$ & $-0.138 *$ & $-0.053 * *$ \\
\hline$\beta_{52}$ & $-0.147^{*}$ & -0.041 \\
\hline$\beta_{53}$ & $-0.235^{*}$ & 0.012 \\
\hline$\beta_{54}$ & $-0.317 *$ & $-0.045 * * *$ \\
\hline \multicolumn{3}{|c|}{ EXC: Changes in exchange rates } \\
\hline$\beta_{61}$ & $0.750 *$ & $-3.276^{*}$ \\
\hline$\beta_{62}$ & $0.741 *$ & $-3.984 *$ \\
\hline$\beta_{63}$ & $0.969 *$ & $-4.448^{*}$ \\
\hline$\beta_{64}$ & $0.973 *$ & $-5.114^{*}$ \\
\hline \multicolumn{3}{|c|}{$\triangle I N T$ : Changes in the regional interest rates } \\
\hline$\beta_{71}$ & -1.918 & 0.291 \\
\hline$\beta_{72}$ & 1.658 & 0.160 \\
\hline$\beta_{73}$ & 2.965 & -4.456 \\
\hline$\beta_{74}$ & 0.973 & -0.848 \\
\hline \multicolumn{3}{|c|}{ VOL: Regional stock market volatility } \\
\hline$\beta_{81}$ & $0.131 *$ & $0.042 *$ \\
\hline$\beta_{82}$ & $0.133^{*}$ & 0.039 \\
\hline$\beta_{83}$ & $0.256^{*}$ & -0.020 \\
\hline$\beta_{84}$ & $0.350 *$ & $0.080 *$ \\
\hline
\end{tabular}




\begin{tabular}{lrr}
\hline Log-likelihood & -1069.540 & -1020.796 \\
Pseudo- $R^{2}$ & 0.162 & 0.161 \\
\hline
\end{tabular}

The table shows the results of the multinomial logit regression model for the negative exceedances to test contagion from Euro Area to Asia. The multinomial logit regression model is in the form: $P_{k}=$ $\frac{\exp \left(\beta_{k}^{\prime} x\right)}{1+\sum_{i=1}^{K} \exp \left(\beta_{i}^{\prime} x\right)}$. The exceedances are defined as negative extreme returns that lie below VaR. The number of negative exceedances of Asian stock markets is modelled as the dependent variable in the multinomial logit regression model. The covariates, $x$, include the number of negative coexceedances of Asian stock markets at time $t-1\left(\operatorname{Coexc}_{t-1}\right)$, the change in commodity price index $(\triangle C P I)$, the change in the U.S. long-term interest rates ( $\triangle U$ Srate), TED spread (TED), VIX $(V I X)$, exchange rate return $(E X C)$, the changes in regional shortterm interest rates $(\triangle I N T)$, the volatility of regional index $(V O L) . \beta_{0 i}$ are the intercept coefficients for each category $i$, where $i$ equals 1 to $4 . \beta_{1 i}, \beta_{2 i}, \beta_{3 i}, \beta_{4 i}, \beta_{5 i}, \beta_{6 i}, \beta_{7 i}, \beta_{8 i}$ are the parameters of Count $_{t-1}, \Delta C P I$, $\triangle U$ Srate, TED, VIX, EXC, $\triangle I N T$, and VOL, respectively. *,**, and *** denote significance levels at the $1 \%, 5 \%$, and $10 \%$, respectively. 